This is an electronic reprint of the original article. This reprint may differ from the original in pagination and typographic detail.

Author(s): Tero, Tiia-Riikka; Nissinen, Maija

Title: A perspective to resorcinarene crowns

Year: $\quad 2014$

Version:

Please cite the original version:

Tero, T.-R., \& Nissinen, M. (2014). A perspective to resorcinarene crowns.

Tetrahedron, 70(6), 1111-1123. https://doi.org/10.1016/j.tet.2013.12.057

All material supplied via JYX is protected by copyright and other intellectual property rights, and duplication or sale of all or part of any of the repository collections is not permitted, except that material may be duplicated by you for your research use or educational purposes in electronic or print form. You must obtain permission for any other use. Electronic or print copies may not be offered, whether for sale or otherwise to anyone who is not an authorised user. 


\title{
A Perspective to Resorcinarene Crowns
}

\author{
Tiia-Riikka Tero $^{\mathrm{a}}$ and Maija Nissinen ${ }^{\mathrm{a} *}$ \\ ${ }^{a}$ Nanoscience Center, Department of Chemistry, University of Jyväskylä, P.O. Box 35, FIN-40014 JYU, \\ Finland
}

*Corresponding author. Tel.: +358 50 4280804; e-mail: maija.nissinen@jyu.fi

\begin{abstract}
In this report, we have summarized different synthesis methods of the resorcinarene crowns, discussed their structural and complexation properties together with the possible application aspects.
\end{abstract}

\section{Keywords}

Resorcinarene, Resorcinarene crown, Calix crown, Complexation, Receptor

\section{Introduction}

In supramolecular chemistry crown ethers are one of the oldest and most explored but still today a very intriguing class of compounds. They have a remarkable ability to act as receptors or ionophores for a variety of guest species depending on their chemical and structural properties, which can be modified just by changing the number of oxygen donors, i.e. altering the size of the crown ether, or replacing them with nitrogen or sulfur atoms or by adding additional functional groups, such as aromatic rings as part of the scaffold. These alterations change the geometry of the host and thus binding affinity and selectivity toward guests such as alkali, ${ }^{1}$ alkaline earth ${ }^{2}$ and transition metal cations ${ }^{3}$ and ammonium ions ${ }^{4}$ making crown ethers very useful compounds in designing artificial sensory systems. ${ }^{5}$ The cyclic structure and hydrogen bond donors of crown ethers make them also very useful in the construction of rotaxane and pseudorotaxane-type assemblies and therefore as components for molecular machines and devices. ${ }^{6}$ The crown ether moieties have subsequently been employed as a part of a structure of other supramolecular hosts such as calix[4]arenes to form a group of calix[n]crowns, which have shown to exhibit remarkable ionophoric properties as hosts for alkali and alkali earth metals as well as tertiary amines. ${ }^{7}$

The subclass of calixarene family, namely calix[4]resorcinarenes, or simply resorcinarenes share lot of common features with their close relatives, calix[4]arenes. ${ }^{8}$ Therefore resorcinarenes provide a good but relatively little explored alternative for crown ether functionalization with sufficiently different properties to calix crowns in respect to binding properties and structural features. For example, in case of calixarenes the bridging is limited to the narrow side of the cavity ${ }^{9}$ or alternatively $1,2-$ or 1,3 -alternate conformations (Figure 1), ${ }^{10}$ which in double bridging orient the bridges to the opposite sides of the calixarene core. Both approaches somewhat limit the utilization of the interactions to calixarene core in complexations. With resorcin[4]arenes, on the other hand, the hydroxyl groups are situated at the open end of the cavity which enables the resorcinarene core to take part in the cation binding with cation- $\pi$ interactions (Figure 1). Alternatively the conformation of resorcinarenes can be rigidified into a crown by linking the hydroxyl groups of the upper rim to a cavitand structure which provides a higher degree of preorganization and enables crown ether modification to a position between the upper rim oxygens creating an extended cavity for guest binding. ${ }^{11}$ 

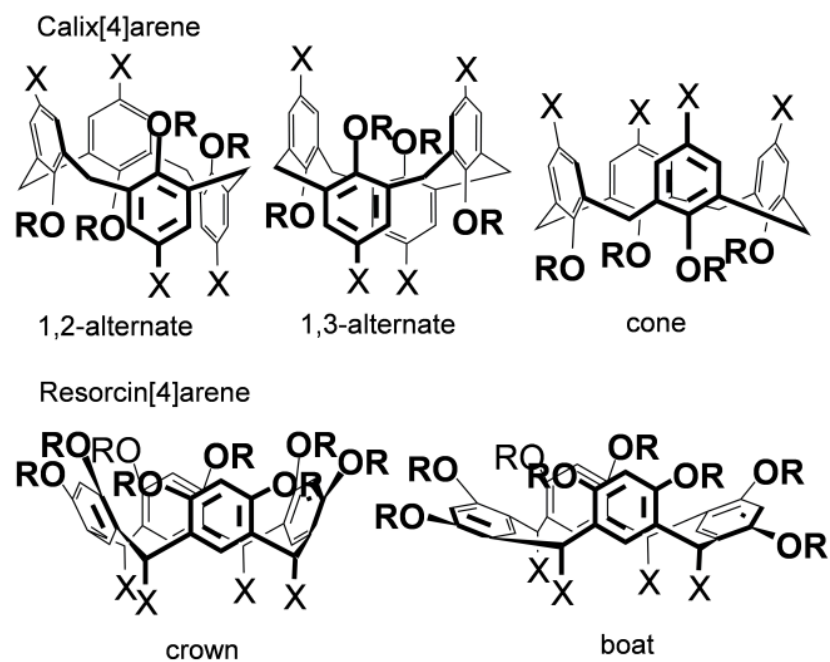

Figure 1. Some examples of typical conformations adopted by calix[4]arenes and resorcin[4]arenes.

This review focuses on the crown ether functionalization of the resorcinarene scaffold and discusses the structural and complexation properties of these compounds. The potential applications of resorcinarene crowns in construction of supramolecular assemblies such as pseudorotaxanes, and solid lipid nanoparticles, as well as their potential as transporter mimics and in antibacterial coatings are reviewed.

\section{Synthesis of resorcinarene crowns}

The skeleton of resorcinarenes differs from calixarenes as it is built form resorcinol units instead of phenols, which enables multiple sites for functionalizations on the upper rim, either to hydroxyl groups or to carbon atoms between them (so called 2-position). ${ }^{8}$ Also the lower rim is accessible for functionalization, either directly during the acid-catalyzed condensation reaction by choosing the suitable functionalized aldehyde as a starting compound, or via post-synthetic modification of the lower rim. All functionalization possibilities have been exploited when designing resorcinarene crown ethers.

\subsection{Bridged resorcinarene crowns}

The most common sites for the crown ether functionalization are the hydroxyl groups of the upper rim of the resorcinarene, which can be bridged to form extended and multifunctional cavities, or substituted by a podand arms having a crown ether part and thus creating a separate binding site outside the resorcinarene cavity. When designing the bridging an important factor to consider is the effect of the bridging on the conformational properties, i.e. how the bridging alters the dimensions and shape of the binding cavity. The other significant factor is the requirement for optimized synthesis of desired products instead a vast number of inseparable isomers, when altogether eight hydroxyl groups are available for attaching the bridges. Therefore, most of the bridged resorcinarene crowns have been made for resorcinarene platforms with inherently limited bridging possibilities, i.e. cavitands or tetramethoxyresorcinarenes. ${ }^{11,12}$

Reinhoudt and co-workers ${ }^{13}$ were the first to study the crown ether bridging with resorcinarenes. Instead of using resorcinarenes with free hydroxyl groups more rigid platform, tetrahydroxy resorcinarene cavitand $\left(\mathrm{R}=\mathrm{C}_{5} \mathrm{H}_{11}\right)$, with four hydroxyl groups at the 2-position available for bridging, was chosen. Alkylation of the tetrahydroxy cavitand ${ }^{14}$ with polyethylene glycol ditosylates afforded two different regioisomers of mono-bridged products: 1,2-bridged crown[n]cavitand (1a-c, $n=5-7)$ and 1,3-bridged crown[6]cavitand (2, Figure 2). The results clearly showed that the alkylation favors the bridging of two hydroxyl groups at the adjacent aromatic rings over the bridging of the opposite aromatic rings as the best yield obtained for 1,2-crown[n]cavitand is $33 \%$ (1b) and only 3\% for 1,3-crown[6]cavitand $\mathbf{2}$. The best 
yields of 1,2-crown[n]cavitand synthesis were obtained for 1,2-crown[6]cavitand 1b (20-33\%) in the reaction of tetrahydroxy cavitand and one equivalent of pentaethylene glycol in the presence of a sodium salt $\left(\mathrm{NaH}\right.$ or $\mathrm{Na}_{2} \mathrm{CO}_{3}$ ) in DMF. With shorter tetraethylene glycol ditosylate the yield of 1,2-crown[5]cavitand 1a was only $8 \%$, whereas a longer hexaethylene glygol ditosylate as a bridging agent gave mono-crown cavitand 1c with a reasonable yield of $20 \%$. These results suggest that the shortness and inflexibility of the tetraethylene glycol ditosylate compared to the longer pentaethylene and hexaethylene glygol ditosylates, makes the bridging reaction more difficult.

The synthesis of 1,3-crown[6]cavitand 2 was done in acetonitrile using $\mathrm{Na}_{2} \mathrm{CO}_{3}$ as a base and also in DMF using $\mathrm{K}_{2} \mathrm{CO}_{3}$ or $\mathrm{Cs}_{2} \mathrm{CO}_{3}$ as a base. The latter conditions also produced a bis-crown derivative 3a in a modest yield of $8-10 \%$ (Figure 2). Few years later Kang et al. ${ }^{15}$ succeeded in synthesizing a biscrown[4]cavitand $\mathbf{3 b}\left(\mathrm{R}=\mathrm{C}_{2} \mathrm{H}_{4} \mathrm{Ph}\right)$ with an improved yield of $25 \%$ (Figure 2). The difference in their synthetic methodology was to use three equivalents of triethylene glycol ditosylate per one equivalent of tetrahydroxycavitand ${ }^{14}$ and $\mathrm{K}_{2} \mathrm{CO}_{3}$ or $\mathrm{Cs}_{2} \mathrm{CO}_{3}$ as a base in DMA.

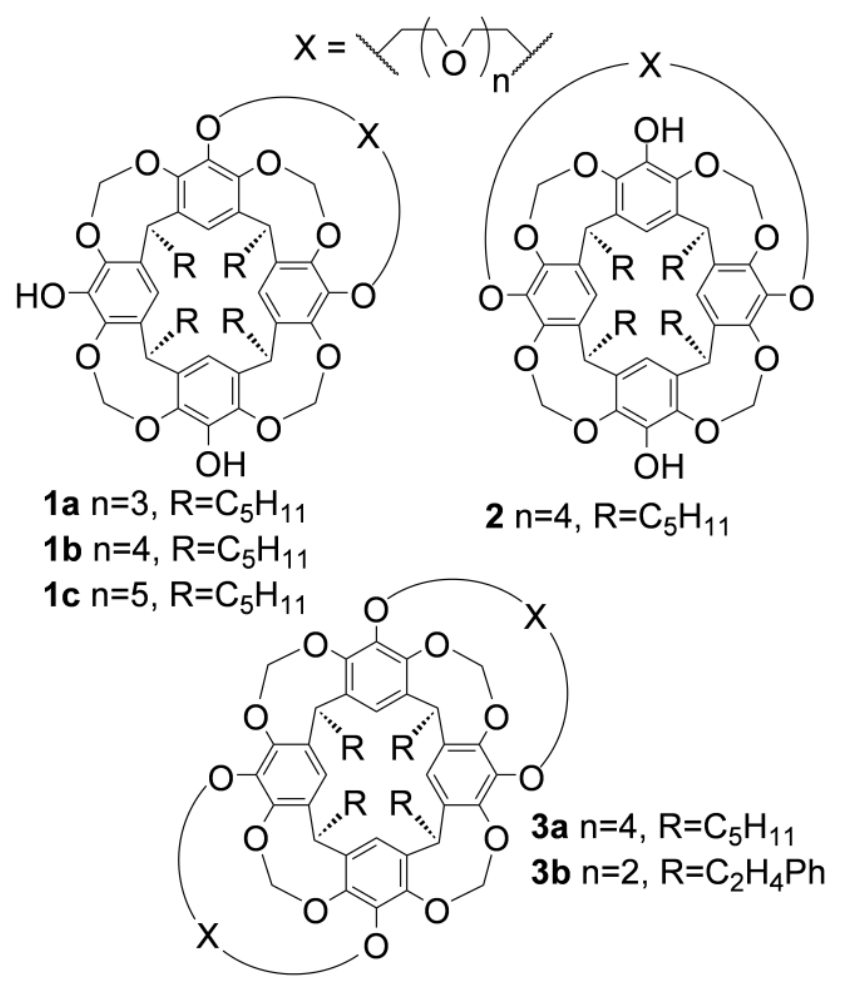

Figure 2. 1,2-crown[n]cavitands, 1,3-crown[6]cavitands and biscrown[n]cavitands $\mathbf{1 a - c , ~} \mathbf{2}$ and 3a-b.

Another alternative for more restricted approach for bridging was to choose tetramethoxy resorcinarene $^{12}$ as a platform for resorcinarene crowns. ${ }^{16,17}$ Tetramethoxy resorcinarene, first synthesized by McIldowie et al. ${ }^{12}$, has only four hydroxyl groups for intramolecular bridging thus reducing the number of possible isomers during the bridging. Tetramethoxy resorcinarene biscrown-4 $4\left(\mathrm{R}=\mathrm{C}_{2} \mathrm{H}_{5}\right)$ and biscrown-5 5a-h $\left(\mathrm{R}=\mathrm{C}_{\mathrm{m}} \mathrm{H}_{2 \mathrm{~m}+1}, \mathrm{~m}=2-5,7,9-11\right)$ were accomplished by a reaction of tetramethoxy resorcinarene with two equivalents of tri- or tetraethylene glycol ditosylates, respectively, in the presence of $\mathrm{Cs}_{2} \mathrm{CO}_{3}$ in DMF with $15-30 \%$ yields (Figure 3 ). The same reaction conditions also produced a mono-bridged tetramethoxy resorcinarene 6a as a side product and the subsequent studies showed that the longer reaction time (60 min vs. $15 \mathrm{~min}$ ) for deprotonating the resorcinarene before the addition of the bridging unit favors the formation of the mono-crown $\mathbf{6 a}$ (optimized yield 13\%, Figure 3). ${ }^{18}$ It was proposed that this is due to the fact that the bridge part, when added in the reaction mixture at the early stage of the deprotonation, can act as a phase 
transfer catalyst, and as such favor the complete deprotonation of the resorcinarene and therefore the formation of bis-crown resorcinarene 5a over mono-crown resorcinarene $6 \mathbf{a}$.

Recently it was discovered that unexpectedly the reaction of tetramethoxy resorcinarene $\left(\mathrm{R}=\mathrm{C}_{2} \mathrm{H}_{5}\right)$ produces a unique mono-crown derivative $\mathbf{6 b}$ as another minor product (yield 5\%, Figure 3$) .{ }^{19}$ Uniqueness of the reaction comes from the modification of the parent aromatic core, which previously has been considered to be virtually intact for changes during the resorcinarene functionalization synthesis. In compound $\mathbf{6 b}$ a benzofuran ring is formed as a part of the macrocycle core. The reaction is proposed to happen via a radical pathway initiated by the formation of DMF radicals in basic conditions. ${ }^{20}$
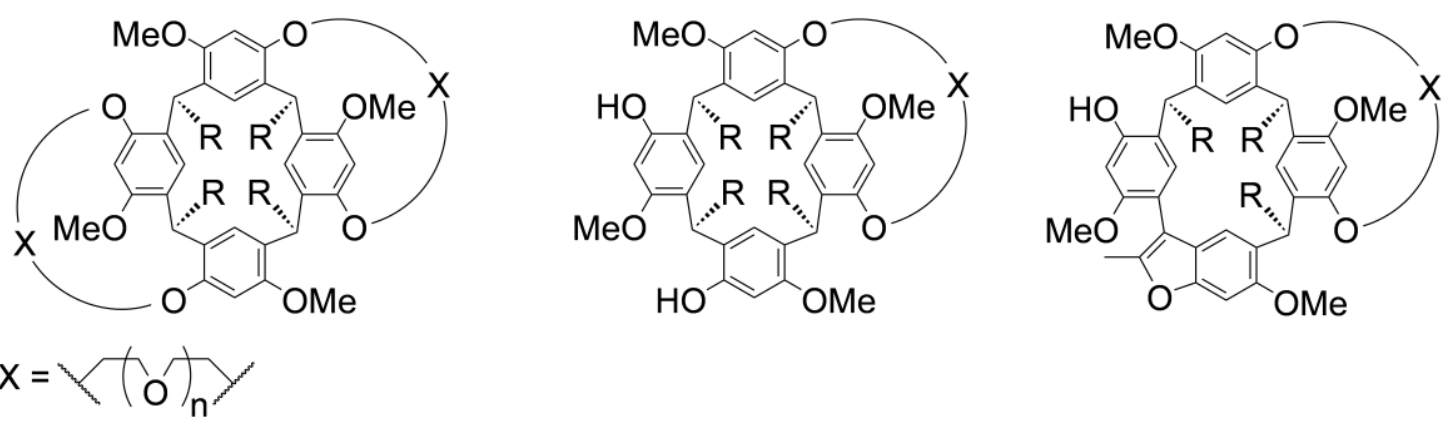

$4 \mathrm{n}=2, \mathrm{R}=\mathrm{C}_{2} \mathrm{H}_{5}$

5a $\mathrm{n}=3, \mathrm{R}=\mathrm{C}_{2} \mathrm{H}_{5} \quad$ 5e $\mathrm{n}=3, \mathrm{R}=\mathrm{C}_{7} \mathrm{H}_{15}$

6a $n=3, R=C_{2} H_{5}$

6b $n=3, R=\mathrm{C}_{2} \mathrm{H}_{5}$

5b $n=3, R=\mathrm{C}_{3} \mathrm{H}_{7} \quad \mathbf{5 f} \mathrm{n}=3, \mathrm{R}=\mathrm{C}_{9} \mathrm{H}_{19}$

$\mathbf{5 c} \mathrm{n}=3, \mathrm{R}=\mathrm{C}_{4} \mathrm{H}_{9} \quad \mathbf{5 g ~ n}=3, \mathrm{R}=\mathrm{C}_{10} \mathrm{H}_{21}$

$\mathbf{5 d} n=3, \mathrm{R}=\mathrm{C}_{5} \mathrm{H}_{11} \quad 5 \mathrm{~h} \mathrm{n}=3, \mathrm{R}=\mathrm{C}_{11} \mathrm{H}_{23}$

Figure 3. Tetramethoxy resorcinarene bis- and mono-crown ethers 4-6.

The octahydroxyl resorcinarene $\left(\mathrm{R}=\mathrm{C}_{5} \mathrm{H}_{11}\right)$ with all eight hydroxyl groups available for bridging was used as a platform by Gutierrez-Tunstad and co-workers (Scheme 1). ${ }^{21}$ As expected, multiple reaction sites complicated the reaction pathway since a direct bridging method where the octahydroxyl resorcinarene was let to react directly with the triethylene glycol ditosylate bridge did not produce desired product. However, when using diquinoxaline cavitand $7^{22}$ as a starting platform to halve the possible reaction sites desired bis-crown $\mathbf{8 a}-\mathbf{b}$ and tetra-crown $\mathbf{9}$ derivatives, called as "cloverleaf" resorcinarenes due to their resemblance to clovers, were obtained. The bridging followed the typical base catalyzed reaction protocol with the reaction of tri- or tetraethylene glycol ditosylates and diquinoxaline resorcinarene $\mathbf{7}$ in $\mathrm{THF}$, after which the quinoxaline protection was removed to obtain bis-crown derivatives $\mathbf{8 a}-\mathbf{b}$ with yields $68 \%$ and $73 \%$, respectively. Bis-crown derivative $\mathbf{8 b}$ was then carried out to a second bridging with triethylene glycol ditosylate which finally afforded tetracrown derivative 9 in a $25 \%$ yield. 


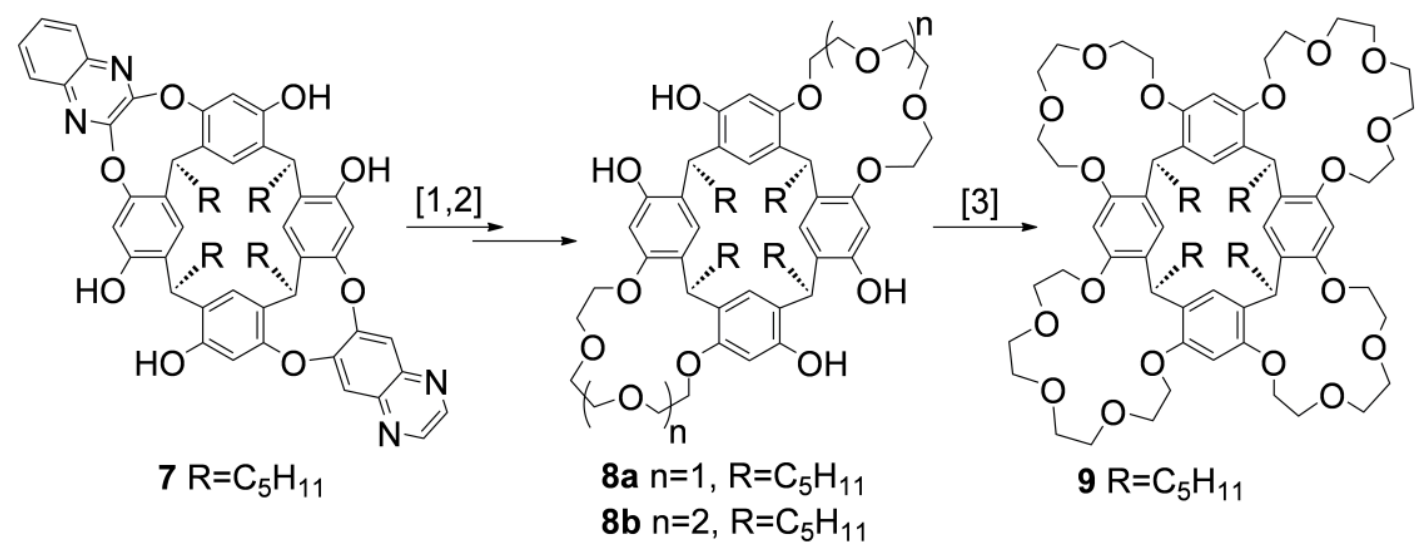

Scheme 1. Synthesis of "cloverleaf" resorcinarene crown ethers $\mathbf{8 a}-\mathbf{b}$ and $\mathbf{9}$ from diquinoxaline cavitand 7.

[1] tri/tetraethylene glycol ditosylate, $\mathrm{Cs}_{2} \mathrm{CO}_{3}$, THF; [2] catechol, $\mathrm{CsF}$, DMF; [3] triethylene glycol ditosylate, $\mathrm{Cs}_{2} \mathrm{CO}_{3}$, THF.

In order to alter the complexation properties of the resorcinarene crowns, a few examples of modification of the functionality of the crown ether bridge have been made. To improve the selectivity towards certain alkali metal cations and to explore the effect of cation- $\pi$ interactions for cation binding aromatic functionality was introduced in the crown ether bridge (compounds 10a-b, Figure 4). ${ }^{23}$ The resorcinarene derivatives were accomplished by a similar reaction procedure to bis-crown derivatives $\mathbf{4}$ and $\mathbf{5 a}-\mathbf{h}$, which afforded products $\mathbf{1 0 a}$ and $\mathbf{1 0 b}$ with yields of $18 \%$ and $42 \%$, respectively.

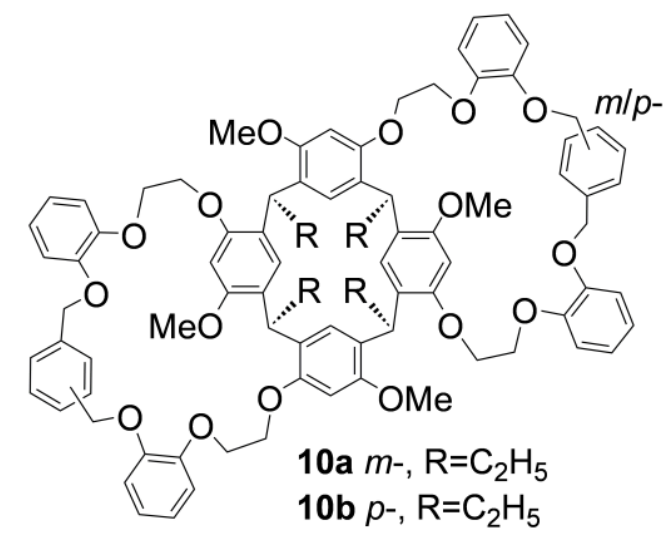

Figure 4. Tetramethoxy resorcinarene $m$ - 10a and $p$-tribenzo-bis-crowns $\mathbf{1 0 b}$.

In order to improve the binding towards softer metals, such as silver, thiacrown derivatives of bis-crown resorcinarenes were synthesized. ${ }^{24}$ Bis-thiacrowns 12a and 12b (yields 21-24\%) were achieved via two step reaction by first synthetizing tetratosyl derivative 11, which was then let to react with two equivalents of 2-mercaptoethyl ether or bis-(2-mercaptoethyl)sulfide in acetonitrile in the presence of $t \mathrm{BuOK}$ (Scheme 2a).

An earlier example of thiacrown derivatives was presented by Morikawa et al. ${ }^{25}$ in late $1990 \mathrm{~s}$. In their compounds a single bridge is attached via condensation reaction of 1,3-dibromoresorcinarene with 2-mercaptoethyl ether, propane-1,3-dithiol or ethane-1,2-dithiol in the presence of large excess of formaldehyde to the 2-position of the opposite aromatic rings to produce basket-like mono-thiacrowns 13ad with $13-47 \%$ yields (Scheme $2 b$ ). 
a)

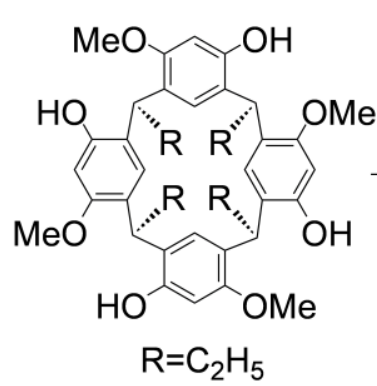

b)
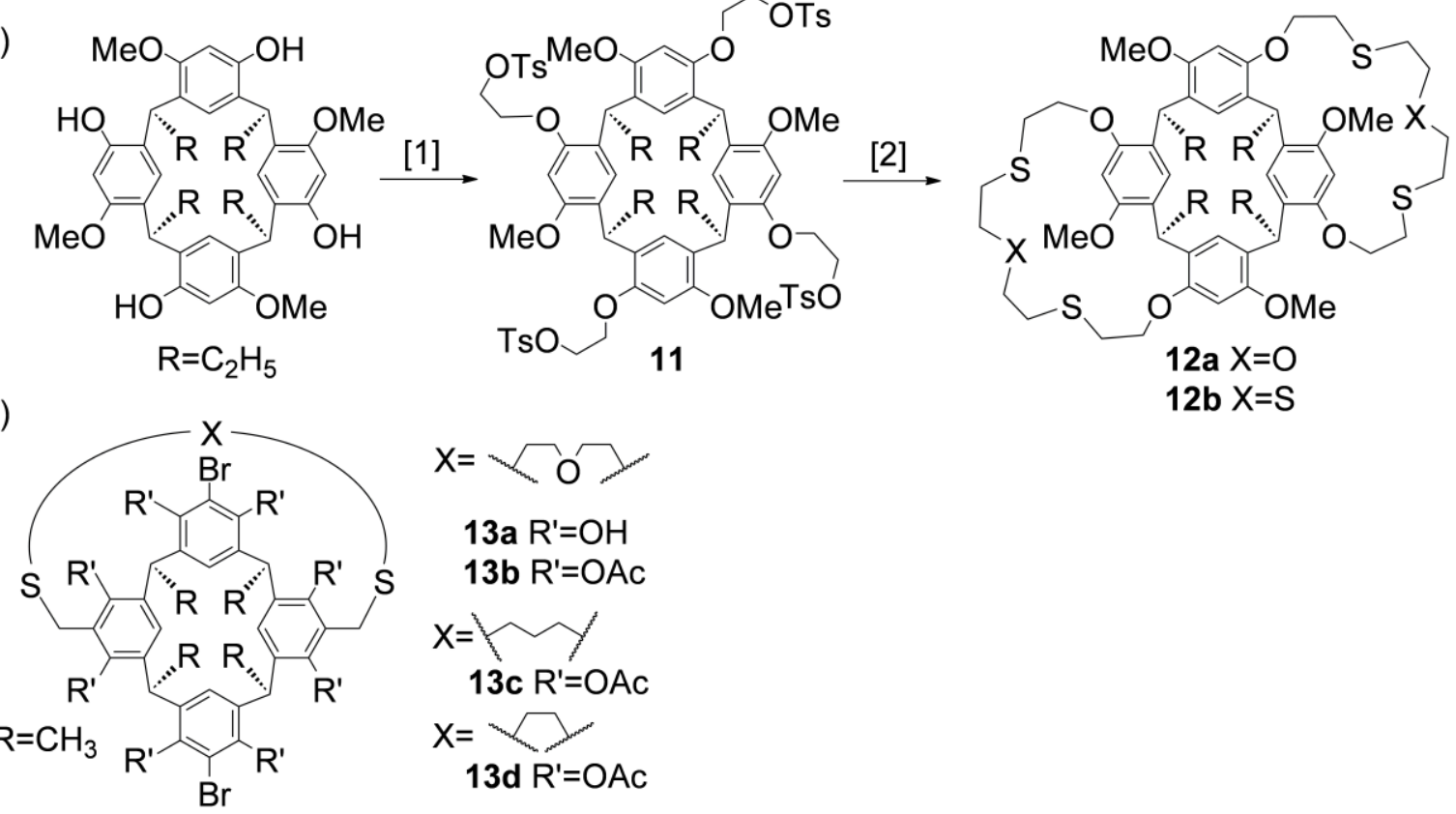

13d $R^{\prime}=O A c$

Scheme 2. a) Synthesis of resorcinarene bis-thiacrowns $\mathbf{1 2 a}-\mathbf{b} ;[1] \mathrm{Cs}_{2} \mathrm{CO}_{3}$, ethylene glycol ditosylate and dibenzo[18]crown-6 in acetonitrile; [2] $\mathrm{KO} t \mathrm{Bu}, 2$-mercaptoethyl ether/bis-(2-mercaptoethyl)sulfide in acetonitrile, and $b$ ) the structure of mono-thiacrowns $\mathbf{1 3 a - d}$.

\subsection{Podand-type resorcinarene crowns}

Another way to a add crown ether functionality to resorcinarene platforms is to add a cyclic crown ether moiety as a podand-type of arm to resorcinarene cavitands. Crown ether rings are inserted to the aromatic carbon at 2-position between the oxygen atoms of the upper rim with nitrogen serving as a pivot atom for attaching. Hamada et al. ${ }^{26}$ were the first to report podand-type resorcinarene mono- and bisazacrown ethers 14a and $15\left(\mathrm{R}=\mathrm{CH}_{3}\right.$, Figure 5). The reaction was a two-step regioselective synthesis with mono- and 1,3-bis-chloromethylated cavitand intermediates which after treatment with aza-15-crown-5 and $\mathrm{K}_{2} \mathrm{CO}_{3}$ in DMF afforded azacrown cavitand derivatives $\mathbf{1 4 a}$ and 15 with $30 \%$ yields. A similar procedure was applied to the synthesis of aza- $n$-crown- $m$ ethers $\mathbf{1 4 b}$ and $\mathbf{1 4 c}\left(n=21\right.$ or $15, m=7$ or $5 ; \mathrm{R}=\mathrm{C}_{11} \mathrm{H}_{23}$, Figure 5) with a fused fluorescent methyl coumarine moiety. ${ }^{27,28}$ The fluorescent podand derivatives $\mathbf{1 4 b}$ and $\mathbf{1 4 c}$ were obtained with yields of 60 and $10 \%$, respectively.

Tetrasubstituted resorcinarene cavitand crowns $\mathbf{1 6 a}$ and 16b with four crown ether binding sites above the aromatic resorcinarene cavity are synthetized similarly to their mono-crown derivatives (Figure 5). Lamb et al. ${ }^{29}$ attached aza-18-crown-6 into a tetrabenzyl-bromo cavitand ${ }^{30}$ to get a compound 16a with a remarkable $98 \%$ yield. Ihm and Paek's ${ }^{31}$ tetrakis(dibenzo-25-crown-8)-cavitand 16b was obtained in $74 \%$ yield from a refluxing mixture of tetrahydroxy cavitand, bromomethyldibenzo-25-crown-4 and $\mathrm{K}_{2} \mathrm{CO}_{3}$ in acetone. 

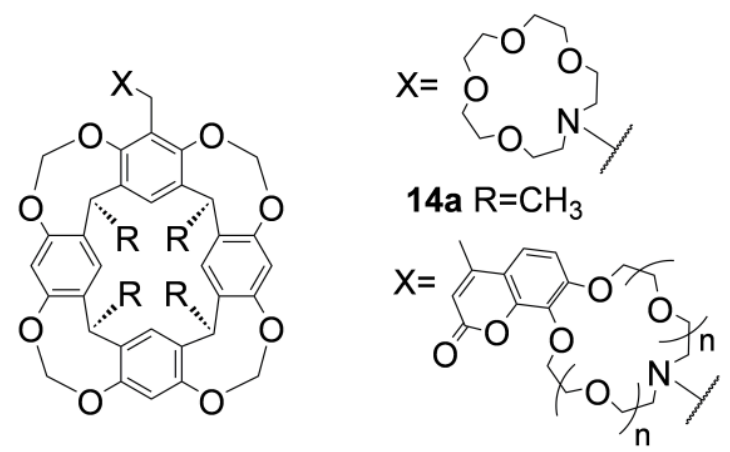

$14 b n=1, R=C_{11} H_{23}$

$14 \mathrm{c} n=2, R=\mathrm{C}_{11} \mathrm{H}_{23}$

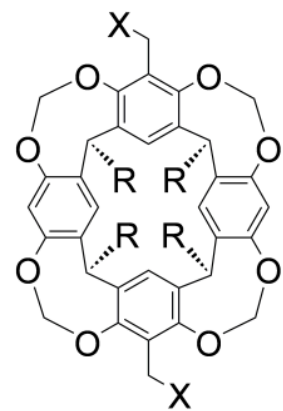<smiles>[Y]C1CCOCCOCCN(CC)CCOCCOC1</smiles>

$15 \mathrm{R}=\mathrm{CH}_{3}$

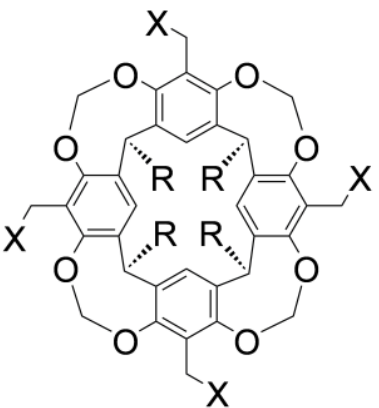

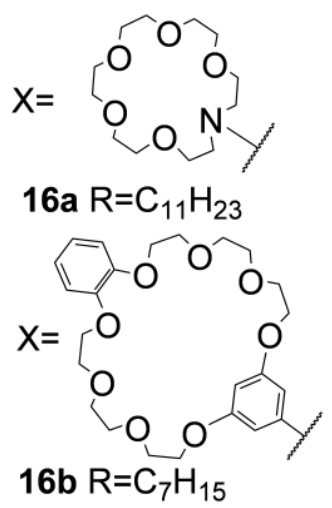

Figure 5. Mono-, bis- and tetrasubstituted 14-16 cavitand crowns.

\subsection{Lower rim crown ether resorcinarenes}

The favourable properties of resorcinarenes, i.e. amphiphilicity and thus a capacity to form bilayers and a cyclic structure to allow the passage of ions, motivated Beer and co-workers ${ }^{32}$ to choose resorcinarenes as platforms for their ion channel research. Unlike previous crown ether functionalized resorcinarenes, the crown ether moieties were attached as part of the lower rim (17a-b and 18a-b, Figure 6) in the original resorcinarene core synthesis $^{33}$ by using 4'-formylbenzo[15]crown-5 and 4'formylbenzo[18]crown- 6 as aldehydes in the condensation reaction with resorcinol. This procedure afforded resorcinarenes $\mathbf{1 7 a}-\mathbf{b}$ with 73 and $93 \%$ yields. To improve the solubility in halogenated solvents, the hydroxyl groups of the upper rim of $\mathbf{1 7 a}-\mathbf{b}$ were acylated affording the derivatives $\mathbf{1 8 a}-\mathbf{b}$ (66 and $74 \%$ yields). 


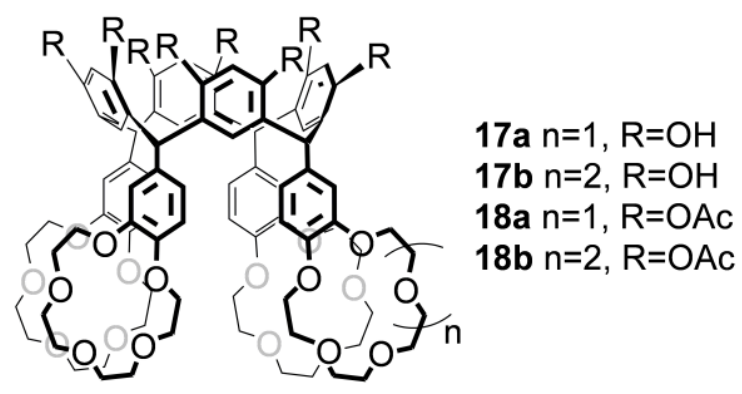

Figure 6. Crown ether resorcinarenes $17 \mathbf{a}-\mathbf{b}$ and their acylated derivatives $\mathbf{1 8 a}-\mathbf{b}$.

Photoswitchable functional groups as part of a resorcinarene scaffold enables building different kinds of phototunable molecular devices. The structure of the lower rim crown ether resorcinarene derivative $\mathbf{1 7} \mathbf{a}^{32}$ known to act as a potassium transporter was modified by introducing an azo benzene group between the macrocycle and the crown-5 moiety (Figure 7). ${ }^{34}$ The tetra-substituted derivative 19a was synthetized by a condensation reaction of an azobenzo[15]crown-5 aldehyde with an equimolar amount of resorcinol in ethanol $\mathrm{HCl}$ acting as a catalyst (35\% yield). The same reaction conditions with two equivalents of resorcinol and one equivalent of the azobenzo[15]crown-5 moiety afforded a dimeric compound consisting of two resorcinol units attached together via methine bridge with the azobenzo[15]crown-5 "leg". Subsequently, the condensation reaction of the dimeric compound with octyl aldehyde gave the bis-substituted azobenzo[15]crown-5 resorcinarene derivative 19b with $16 \%$ yield.

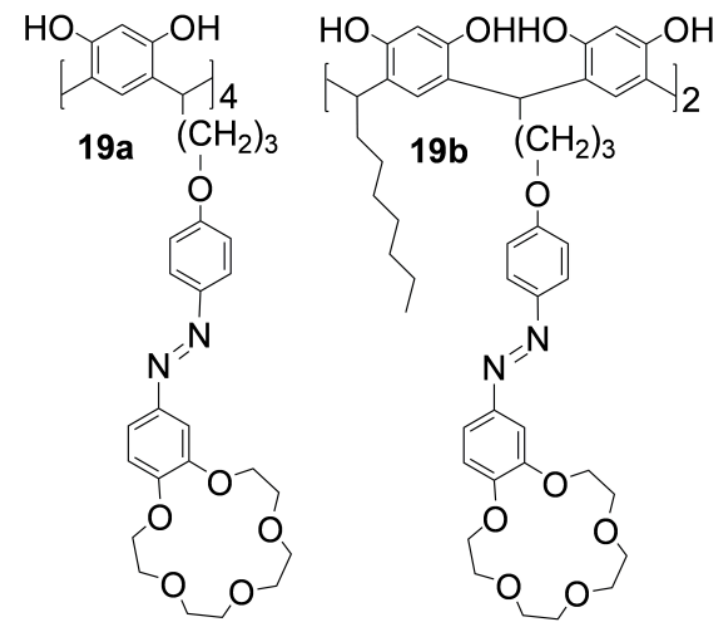

Figure 7. Azobenzo[15]crown-5 resorcinarenes 19a-b.

\section{Structural properties}

NMR spectroscopy and X-ray crystallography are the most commonly used experimental methods to study the structure and conformations of the resorcinarene crowns. The foremost structural difference between cavitands and resorcinarenes with free hydroxyl groups is that the cavitand bridges force the macrocycle into a rigid and symmetrical crown shaped conformation, whereas resorcinarenes with free hydroxyl groups are more flexible to adopt different conformations. These properties are directly transferred to resorcinarene crown derivatives depending on the platform chosen as is evidenced by the crystal structure of 1,2-bridged crown[6]cavitand 1b (CCDC 101145): the cavitand core is a $C_{4 \mathrm{v}}$ symmetrical crown conformation and the crown ether bridge, forming a separate extension to the cavity, adopts a slightly oval 
shape with an average diameter ${ }^{35}$ of $5.68-7.24 \AA$ (Figure 8 ). $\dagger^{13}$ The cavity acts as a separate binding site for a molecule of ethanol situated in the middle of the cavity and the crown moiety binds two water molecules.

Kang et al. ${ }^{15}$ used a Monte Carlo conformation search with MMFF force field to study the optimized structure of the bis-crown[4]cavitand $\mathbf{3 b}$. To simplify the calculations the $\mathrm{CH}_{2} \mathrm{CH}_{2} \mathrm{Ph}$ groups of the lower rim were replaced with methyl groups. The lowest energy conformation of the structure has a $C_{2}$ symmetry due to the bis-bridging. The conformation of the cavitand core follows the crystal structure of $\mathbf{1 b}^{13}$ with $\mathrm{OCH}_{2} \mathrm{O}$ bridges bent similarly toward the cavity. As expected, both of the crown ether bridges of cavitand $\mathbf{3 b}$ are more bent over the macrocyclic ring compared to the structure of $\mathbf{1 b}$ as the crown bridge moiety is six atoms shorter.
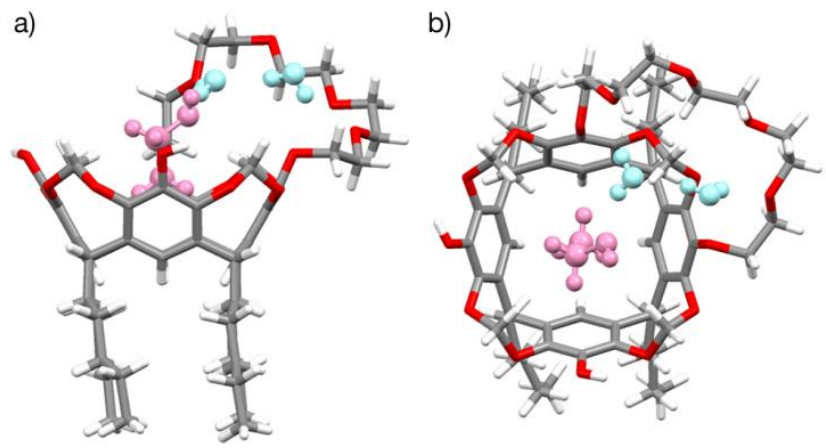

Figure 8. Crystal structure of the 1,2-bridged crown[6]cavitand 1b, a) side and b) top views. Ethanol is occupying the cavitand whereas the crown moiety binds two water molecules. ${ }^{13}$

The crown ether bridging of tetramethoxy resorcinarenes 4-6 and $\mathbf{1 0}$ causes the inhibition of the upper rim hydrogen bonds and thus the symmetry of the macrocycle is reduced to boat conformation with a rectangular shaped cavity. ${ }^{16-18,23,36}$ The crown ether bridges lock the boat conformation which is seen in ${ }^{1} \mathrm{H}$ NMR as two set of resonances for the aromatic signals in different chemical environments. The crystal structures obtained for bis-crowns 4, 5a, 5c-d (CCDC 624294-624295, 718576-718577, 854053-854054) and mono-crown 6a (CCDC 735046-735048) confirmed the boat conformation in all cases. Depending on the solvent included in the binding cavity and the packing motif the macrocycle adopts either an ideal or slightly twisted boat conformation. The crown bridges together with the horizontal aromatic rings form a circular pocket shaped cavity with an average diameter of $6.05-6.31 \AA$ for bis-crown-5 derivatives and explicitly smaller diameter (4.40-4.51 $\AA$ ) for the cavity of the bis-crown-4 derivative 4 . As mono-crown derivative 6a has only one bridge and the other end of the resorcinarene macrocycle is left open, the entire cavity is more accessible compared to the bis-crown derivatives 5a and 5c-d (Figure 9b) and it virtually has two different kinds of binding sites, one with crown ether functionality and other with free hydroxyls capable of hydrogen bonding. ${ }^{18}$

The effect of the aromatic rings as part of the crown ether moiety for the conformation of the binding sites was seen in the crystal structures of tribenzo-bis-crowns $\mathbf{1 0 a}$ and $\mathbf{1 0 b}{ }^{23}$ The binding cavity of $m$-tribenzo-bis-crown 10a (CCDC 658268-658269) is more oval but its average cavity diameter does not differ that much (5.58-5.68/6.29-6.37 $\AA$, Figure 9c) from cavity of bis-crown-5 5. However, since the longer bridge of $10 \mathbf{a}$ has more freedom to change its conformation the degree of preorganization is diminished in spite of the rigid aromatic ring. The structure of $p$-tribenzo-bis-crown 10b (CCDC 658270658271) is very different from all other bis-crowns: the crown ether moieties are spread out over the upright aromatic rings, instead of encircling and enlarging the open ends of the cavity (Figure 9d). Therefore the crown moieties do not basically provide any meaningful benefit for the binding properties of the host, which

$\dagger$ Distance of the centroids of the opposite aromatic rings is $6.5 / 6.7 \AA$. 
is further evidenced by the variable temperature NMR experiments which showed that the structure of $p$ tribenzo-bis-crown $\mathbf{1 0 b}$ is very rigid in contrast to the flexible $m$-tribenzo-bis-crown 10a.

a)
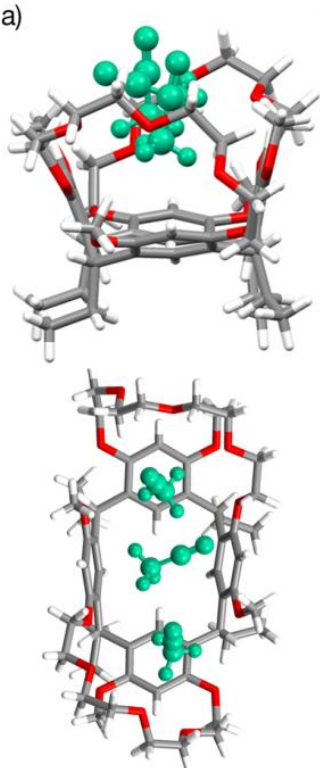
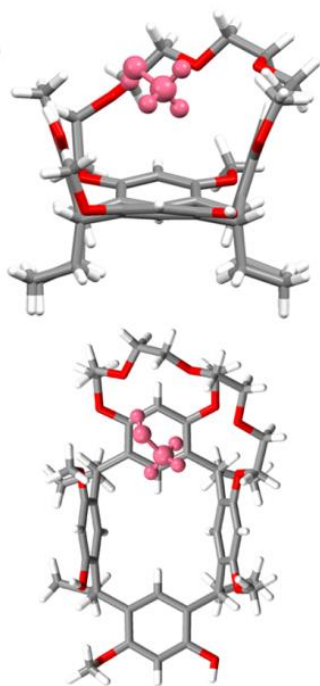

c)

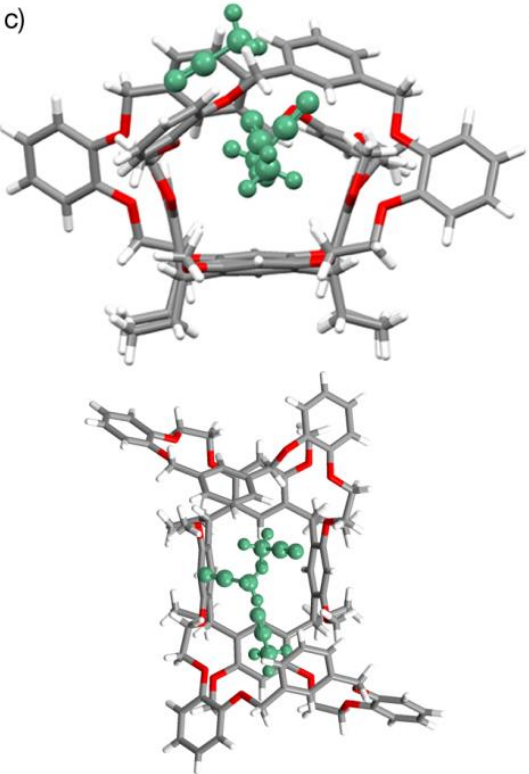

d)

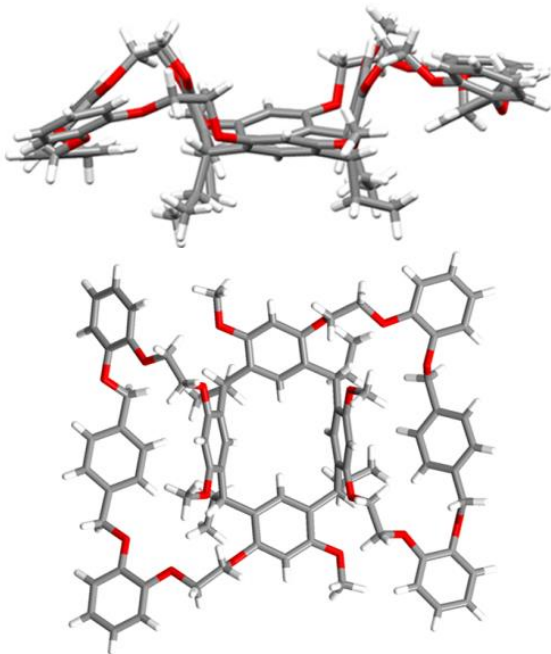

Figure 9. Front and top views of the cavities and binding pockets of tetramethoxy resorcinarene a) bis-crown 5a, b) mono-crown $\mathbf{6 a}, c) m$ - 10a and d) $p$-tribenzo-bis-crowns $\mathbf{1 0 b}$ in solid state. ${ }^{16,18,23}$

The solid state structures of the bis-thiacrowns 12a and $\mathbf{1 2 b}$ are very similar to their crown ether analog: the macrocycle core is in a boat conformation the thiacrown moieties encircling both ends of the cavity (CCDC 855777-855778, Figure 10a and b). ${ }^{24}$ However, the crown pockets (an average diameter of 5.10-5.25 $\AA$ ) are more elongated than their oxygen analogs because the sulfur atoms turn away from the cavity (exodentate), whereas in the structures of $\mathbf{5}$ oxygens are oriented toward the cavity (endodentate). The orientation of the sulfur atoms therefore elongates the shape of the crown moiety by causing the anti conformation of ethylene units $\left(\mathrm{S}-\mathrm{CH}_{2} \mathrm{CH}_{2}-\mathrm{S} / \mathrm{O}\right.$, torsion angle $\left.\sim 180^{\circ}\right)$, whereas with the oxygen bridge the ethylene units $\left(\mathrm{O}-\mathrm{CH}_{2} \mathrm{CH}_{2}-\mathrm{O}\right.$, torsion angle $\left.\sim 60^{\circ}\right)$ are all in a gauche conformation causing a more circular binding site (Figure 10c). 
a)

b)

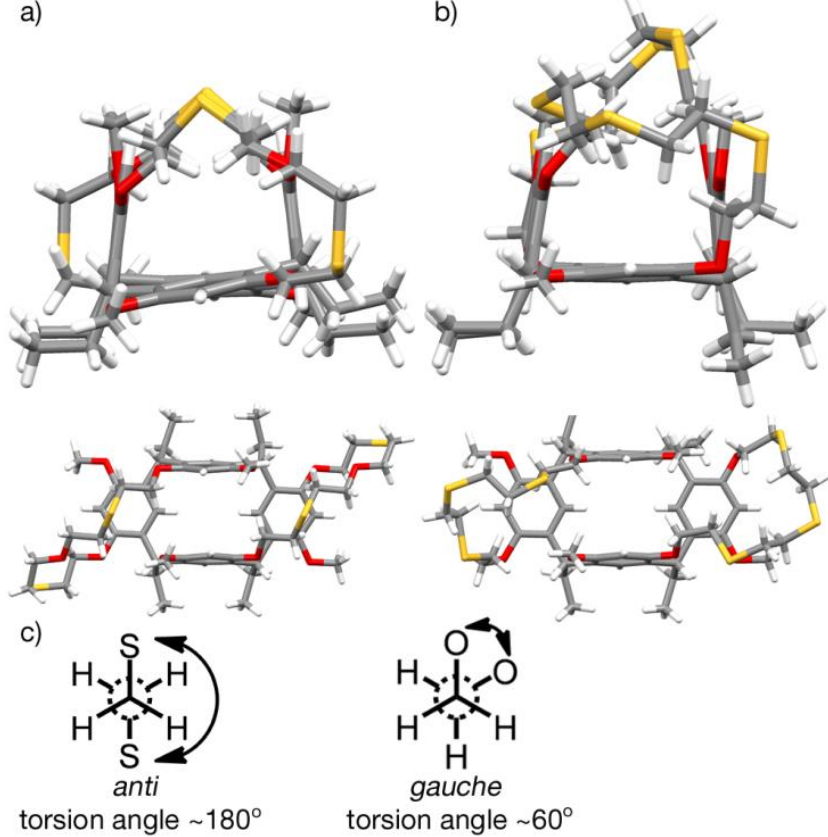

Figure 10. Front and top views of a) bis-dithiacrown 12a and b) bis-trithiacrown 12b. c) Anti and gauche orientations of the ethylene units in crown moieties. ${ }^{24}$

The conformational properties of mono-thiacrowns $13 \mathbf{a}-\mathbf{d}^{25}$ were concluded by ${ }^{1} \mathrm{H}$ NMR spectroscopy from the chemical shift differences $(\Delta \delta)$ between the two types of intraannular aromatic protons of the macrocycles. ${ }^{33,37}$ The chemical shifts of mono-thiacrown 13a $(\Delta \delta=0.52 \mathrm{ppm})$ suggest a flattened crown conformation over a boat conformation as the upper rim hydroxyl groups can still form stabilizing hydrogen bonds. As expected the acetylated mono-thiacrown 13b adopts a boat conformation $(1.35 \mathrm{ppm})$ in which the bridged aromatic rings are in upright position and the brominated are horizontal. However, in the case of shorter bridged mono-thiacrowns $13 \mathbf{c}$ and 13d $(\Delta \delta=0.97 \mathrm{ppm}$ and $1.10 \mathrm{ppm}$, respectively) with acetyl groups the conformation was proposed to be a flattened cone despite the lack of upper rim hydrogen bonds. The molecular modeling considerations indicated that short bridges are not flexible and thus the steric compression of the bridges fixes the conformation into a flattened cone, which may also be considered as an intermediate in a gradual change of conformation from crown to boat.

\section{Receptor properties}

Cation binding and comparison to closely related calix crowns have been a driving force for developing resorcinarene crowns. The binding properties of the crown derivatives have mainly been studied by determining association constants by ${ }^{1} \mathrm{H}$ NMR or UV-Vis spectroscopic titration, but also more indicative picrate extraction method has been used. An important tool has also been X-ray crystallography, which gives detailed information about the binding interactions and conformational aspects of complexation in solid state. Typical guest species have been alkali metals and silver, but also a few examples of binding of organic ammonium cations are known.

\subsection{Complexation in solution}

The suggestive picrate extraction experiments has mainly been used as a preliminary method for exploring complexation affinity after which the results have been utilized in designing more detailed complexation experiments by spectroscopic methods. A series of alkali metals were tested with bis-crown derivatives 4, 5a, 10a, 10b and mono-crown 6a. ${ }^{16,18,23}$ Resorcinarene crown $\mathbf{4}$ did not bind any alkali metal cations presumably due its small cavity, whereas the openness of mono-crown cavity in $\mathbf{6 a}$ and rigidness and 
lack of suitable binding cavity in $\mathbf{1 0 b}$, as evidenced by single crystal X-ray structure, prohibited binding and therefore picrate extraction. The larger bis-crown derivative $\mathbf{5 a}$ bound $\mathrm{K}^{+}, \mathrm{Rb}^{+}$and $\mathrm{Cs}^{+}$cations with a higher affinity toward the two latter, whereas $\mathbf{1 0 a}$ bound only $\mathrm{Cs}^{+}$indicating selectivity. Picrate extraction studies with a cavitand bis-crown derivative $3 \mathbf{b}$ implied its capacity to extract $\mathrm{NH}_{4}{ }^{+}$in addition to $\mathrm{Na}^{+}, \mathrm{K}^{+}, \mathrm{Rb}^{+}$and $\mathrm{Cs}^{+}$in which $\mathrm{Na}^{+}$complex shows better selectivity over the other ions examined.. ${ }^{15}$

The ${ }^{1} \mathrm{H}$ NMR titration studies of resorcinarene bis-crowns $\mathbf{5 a}$ and 10a confirmed binding of alkali metal cations $\mathrm{K}^{+}, \mathrm{Rb}^{+}$and $\mathrm{Cs}^{+}$in solution with a clear preference to $\mathrm{Cs}^{+}$whereas $\mathrm{Li}^{+}$and $\mathrm{Na}^{+}$were discovered to be too small for resorcinarene crowns already in the preliminary studies with $\mathbf{5 a}$ (Table 1). ${ }^{23}$ Even though the aromatic functionality of the crown part of $\mathbf{1 0 a}$ did not affect the affinity toward $\mathrm{Cs}^{+}(\log$ $\mathrm{K}_{11}(\mathbf{5 a})=1.80 \mathrm{M}^{-1}$ vs. $\left.\log \mathrm{K}_{11}(\mathbf{1 0 a})=1.55 \mathrm{M}^{-1}\right)$ it clearly improved the selectivity toward $\mathrm{Cs}^{+}$as intended. No evidence of a complex formation in the case of $p$-tribenzo-bis-crown $10 \mathbf{b}$ was noticed in ${ }^{1} \mathrm{H}$ NMR either, which was expectable due to the very rigid conformation of the bridges outside the binding cavity.

The binding stoichiometry of the hosts was determined by Job plot analysis. ${ }^{38}$ Although the bis-crown ethers each have two binding sites for cations and the solid state structures (see chapter 4.2) typically show 1:2 host-to-guest binding mode, the titration data of $\mathbf{5 a}$ the had to be fitted to a 1:1 binding model due to the interference of intrinsic water content of the NMR solvent for binding. ${ }^{23}$ It was speculated that either solvation effects of the alkali metal cations or competitive binding of water to crown ether binding site affect the binding of the second cation. In the case of 10a 1:1 model was used due to the solubility problems, which prohibited the accurate determination of stoichiometry. With longer alkyl chain derivatives $\mathbf{5 b}, \mathbf{5 d}, \mathbf{5 f}$ and $\mathbf{5 h}$ no interference of water content of the NMR solvent was observed and the binding studies were focused on binding of cesium alone due to the similarity of the binding site of all biscrown-5 derivatives and the observation that the lower rim does not play a role in cation binding. ${ }^{17}$ Both $1: 1$ and 1:2 complexes with $\mathrm{Cs}^{+}$were seen, $1: 2$ being dominant $\left(\log \mathrm{K}_{11} \mathrm{~K}_{12}=4.06-5.03 \mathrm{M}^{-1}\right)$.

Successful alkali metal binding was also observed with NMR titration of mono-substituted cavitand derivatives $\mathbf{1 4}$. The smallest podand ring 14a indicated 1:1 stoichiometry for a sodium complex (Table 1) and the association constant, $\log \mathrm{K}_{11}=3.5 \mathrm{M}^{-1}$, was determined by UV-vis absorption spectroscopy. ${ }^{26}$ The association constants for mono-substituted cavitand crowns $\mathbf{1 4 b}$ and $\mathbf{1 4 c}$ were determined by an emission titration. ${ }^{27,28}$ The derivative $\mathbf{1 4 b}$ with a slightly smaller crown ring showed affinity toward $\mathrm{Na}^{+}\left(\log \mathrm{K}_{11}=3.08 \mathrm{M}^{-1}\right)$ and $\mathrm{K}^{+}\left(\log \mathrm{K}_{11}=2.70 \mathrm{M}^{-1}\right)$ whereas $14 \mathrm{c}$ bound $\mathrm{Na}^{+}\left(\log \mathrm{K}_{11}=2.46 \mathrm{M}^{-}\right.$ $\left.{ }^{1}\right)$ but its affinity towards larger cations $\mathrm{K}^{+}\left(\log \mathrm{K}_{11}=5.03 \mathrm{M}^{-1}\right), \mathrm{Rb}^{+}\left(\log \mathrm{K}_{11}=4.80 \mathrm{M}^{-1}\right)$ and $\mathrm{Cs}^{+}(\log$ $\mathrm{K}_{11}=4.29 \mathrm{M}^{-1}$ ) was clearly higher. Job plots assured a formation of 1:1 lithium complex for $\mathbf{1 4 b}$ but the association constants could not be determined. The NMR titration of the bis-substituted cavitand $\mathbf{1 5}$ showed a 1:2 complex with $\mathrm{Na}^{+}$, but the association constant was not determined. ${ }^{26}$

Also mono-crown tetramethoxy resorcinarene 6a was tested for alkali metal complexation, but it did not bind any alkali metals as expected from picrate extraction studies (Table 1). ${ }^{18}$ However, its ditopic cavity with crown ether functionality at the one end of the cavity and free hydroxyl group available for hydrogen bond at the other end of the cavity enabled it to form 1:1 complexes with acetyl choline (log $\left.\mathrm{K}_{11}=2.18 \mathrm{M}^{-1}\right)$ and with smaller tetramethyl ammonium cation $\left(\log \mathrm{K}_{11}=1.48 \mathrm{M}^{-1}\right)$.

The complexation studies with bis-crown derivatives $\mathbf{5}$ were expanded from alkali metals to silver due to its antibacterial properties. ${ }^{39,40}$ The association constants of resorcinarene crown ethers $\mathbf{5 a}-\mathbf{b}, \mathbf{5 f}$ and $\mathbf{5 h}$ were promising $\left(\log \mathrm{K}_{11}=1.9 \mathrm{M}^{-1}\right.$ for $\mathbf{2 a}$ and $\log \mathrm{K}_{11} \mathrm{~K}_{12}=4.00-4.13 \mathrm{M}^{-1}$ for $\mathbf{5 b}$, $\mathbf{5 f}$ and $\mathbf{5 h}$ ) and comparable to the binding of cesium in spite of the hardness of binding oxygens. However, the binding 
affinity of silver was substantially increased with thiacrown ethers $(\mathbf{1 2 a}-\mathbf{b})$ giving the association constants of $\log \mathrm{K}_{11} \mathrm{~K}_{12}=8.1$ and 9.2, respectively (Table 1$){ }^{24}$

Table 1. Association constants $\log \mathrm{K}_{11}$ or $\log \mathrm{K}_{11} \mathrm{~K}_{12}\left(\mathrm{M}^{-1}\right)$ for the complexes of $\mathbf{5 a}-\mathbf{b}, \mathbf{5 d}, \mathbf{5 f}, \mathbf{5 h}, \mathbf{6 a}, \mathbf{1 0 a}$ and 12a-b (NMR titrations) and 14a-c (UV-Vis titrations) with different cation guests.

\begin{tabular}{|c|c|c|c|c|c|c|c|}
\hline Compound & $\mathbf{N a}^{+}$ & $\mathbf{K}^{+}$ & $\mathbf{R} \mathbf{b}^{+}$ & $\mathrm{Cs}^{+}$ & $\mathbf{A g}^{+}$ & $\begin{array}{l}\text { Acetyl } \\
\text { choline }\end{array}$ & TMA \\
\hline $\mathbf{5 a}^{a, e}$ & - & 0.23 & 0.65 & 1.8 & 1.9 & - & - \\
\hline $\mathbf{5 b}^{a, f^{\prime}}$ & - & - & - & 4.43 & 4.13 & - & - \\
\hline $\mathbf{5 d}^{a, f}$ & - & - & - & 4.62 & - & - & - \\
\hline $\mathbf{5 f}^{a, f}$ & - & - & - & 4.06 & 4.12 & - & - \\
\hline $\mathbf{5 h}^{a, f}$ & - & - & - & 5.03 & 4.00 & - & - \\
\hline $\mathbf{6 a}^{a, e}$ & - & 0 & 0 & 0 & - & 2.18 & 1.48 \\
\hline $10 \mathbf{a}^{a, f^{\prime}}$ & - & 0 & 0.34 & 1.55 & - & - & - \\
\hline $12 \mathbf{a}^{a, f}$ & - & - & - & - & 8.1 & - & - \\
\hline $12 \mathbf{b}^{a, f}$ & - & - & - & - & 9.2 & - & - \\
\hline $14 \mathbf{a}^{c, e}$ & 3.5 & - & - & - & - & - & - \\
\hline $14 b^{d, e}$ & 3.08 & 2.70 & - & - & - & - & - \\
\hline $14 \mathbf{c}^{d, e}$ & 2.46 & 5.03 & 4.80 & 4.29 & - & - & - \\
\hline
\end{tabular}

\subsection{Solid state complexes}

Even though crystal structures provide an important aspect in complexation studies only the alkali metal and silver complexes of tetramethoxy resorcinarene derivatives $\mathbf{5}$ and $\mathbf{1 2}$ have been more intensively studied by means of crystallography. Typically, the conformation of the resorcinarene scaffold of in complexes of $\mathbf{5}$ is more or less twisted boat depending on the coordinating guest while the two crown ether bridges and the horizontal aromatic rings form the two binding sites. ${ }^{16,17,23}$ Solid state structures of resorcinarene bis-crowns confirm that that the binding pocket is very flexible as it can adopt its shape according to the size of the guest and both alkali metal and silver complexes were crystallized successfully in various solvent conditions.

The structures of solid state alkali metal complexes of resorcinarene bis-crowns $\mathbf{5 a}-\mathbf{h}$ support the association constants obtained in solution, except that also $\mathrm{Na}^{+}$was observed to bind with 5a. Larger alkali metals, $\mathrm{K}^{+}, \mathrm{Cs}^{+}$and $\mathrm{Rb}^{+}$(crystallized as $\mathrm{PF}_{6}^{-}$salts), formed 1:2 complexes with resorcinarene biscrowns 5a (CCDC 624296, 658272-658273, 854055), 5b (CCDC 854056), 5d (CCDC 854057) and 5g (CCDC 854058) and smaller $\mathrm{Na}^{+}$formed an 1:1 host-guest complex with 5a (CCDC 624297, 624298). $\mathrm{K}^{+}$, $\mathrm{Cs}^{+}$and $\mathrm{Rb}^{+}$prefer an endo-binding, i.e. they are located inside the binding cavity having 3 to $4 \mathrm{M}^{+} \ldots \mathrm{O}$ interactions to the crown ether oxygens $(2.4-3.5 \AA)$ and cation $\cdots \pi\left(\eta^{6}\right)$ interaction to their underneath aromatic ring (3.0-3.3 $\AA$, Figure 11a). Sodium cation, on the other hand, binds outside the cavity of 5a (exobinding) coordinating to four crown bridge oxygens of which two belong to the bridge of an adjacent resorcinarene (2.4-2.5 $\AA$ ). This kind of continuous and connecting coordination forms a helical-like chain packing motif (Figure 12).

The host-guest complexes of larger alkali metals $\left(\mathrm{K}^{+}, \mathrm{Cs}^{+}\right)$show a capsular packing motif with two facing resorcinarene hosts encapsulating four metal guests. The capsules formed by longer alkyl chain resorcinarenes $\left(\mathrm{R}=\mathrm{C}_{5} \mathrm{H}_{11}\right.$ and $\left.\mathrm{C}_{10} \mathrm{H}_{21}\right)$ then pack into bilayers (Figure 11b) with polar layer formed by the capsule interior, upper rims of the hosts and counter anions and non-polar layer formed by close packed alkyl chains. The shorter alkyl chain bis-crown complexes also form layer-like structures, but instead of 
forming bilayers the molecules are lined up on top of one another (Figure 11c). The similarity of the packing motif of the different host-guest complexes $\left(\mathbf{5 a} \cdot \mathbf{2} \mathbf{K}^{+}\right.$and $\mathbf{5 a} \cdot \mathbf{2} \mathbf{C s}{ }^{+} ; \mathbf{5 d} \cdot \mathbf{2} \mathbf{K}^{+}$and $\left.\mathbf{5} \mathbf{g} \cdot \mathbf{2} \mathbf{C s}^{+}\right)$implicates that the size of the cation does not play as important role in packing as the solvent or the alkyl chain length.

a)

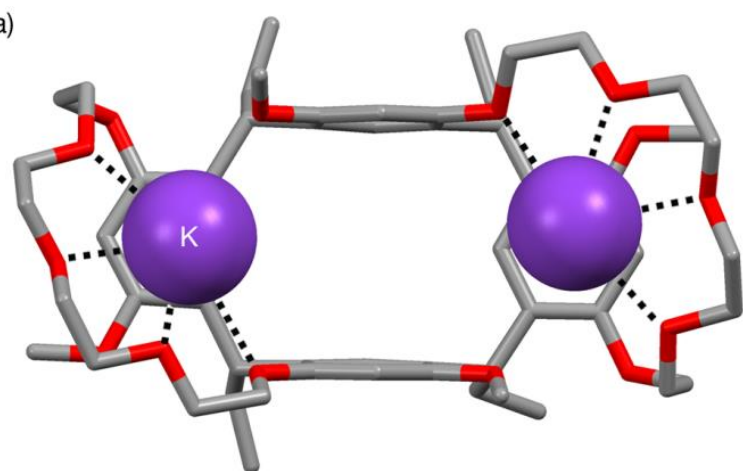

c)

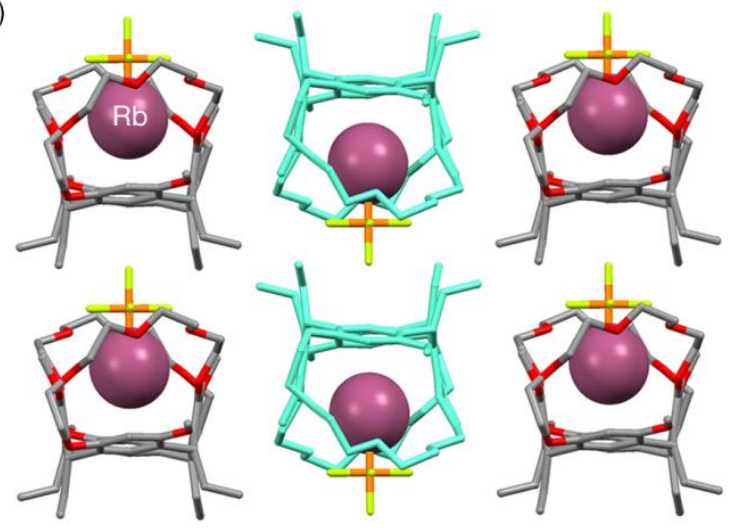

b)
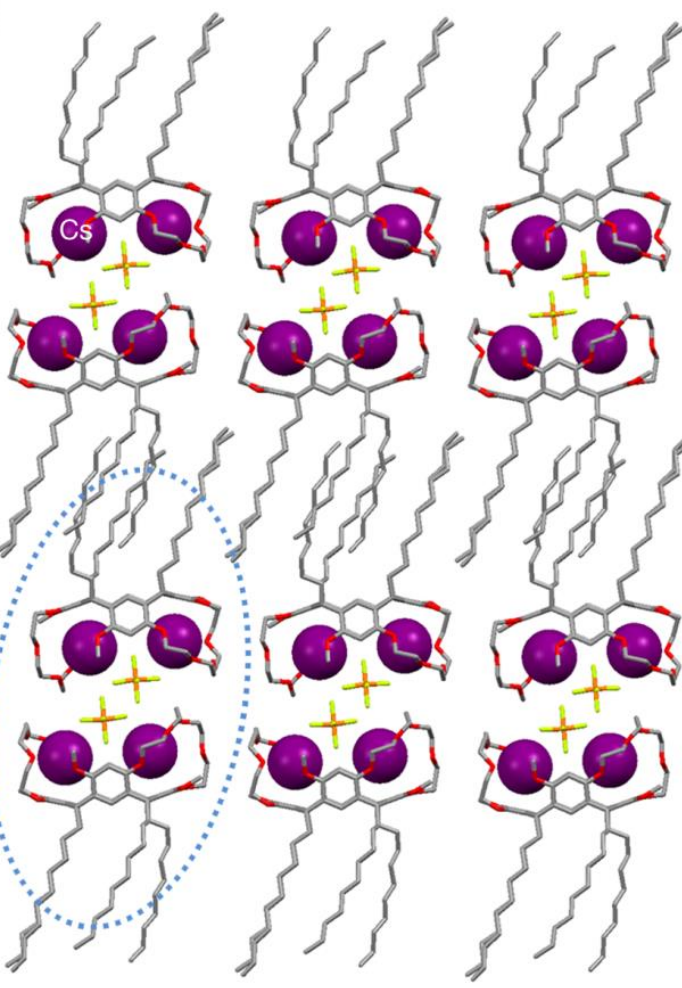
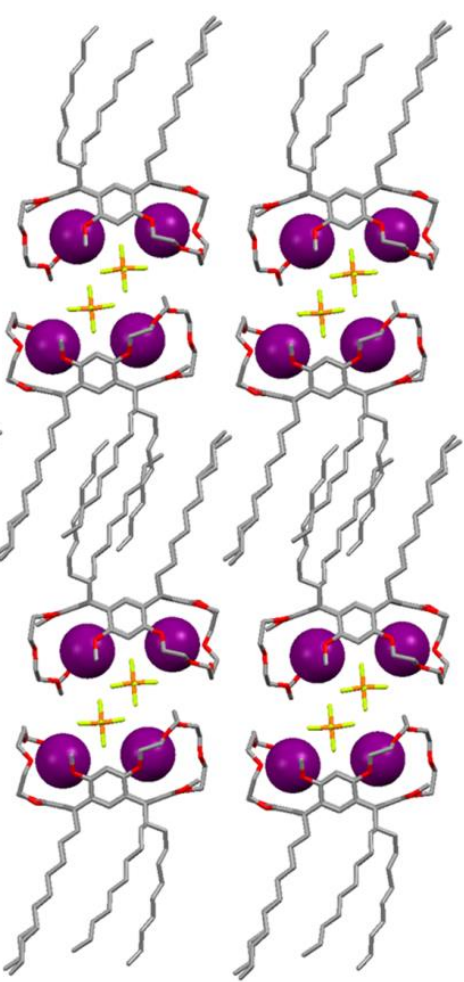

Figure 11. Crystal structures of a) $\mathbf{5} \mathbf{a} \cdot \mathbf{2} \mathbf{K}^{+}$, b) $\mathbf{5} \mathbf{g} \cdot \mathbf{2} \mathbf{C s}^{+}$and c) $\mathbf{5 a} \cdot \mathbf{2} \mathbf{R} \mathbf{b}^{+}$complexes. Hydrogen atoms, solvent molecules and counter anions of a) are omitted for clarity. Capsule structure is circled. ${ }^{16,17,23}$

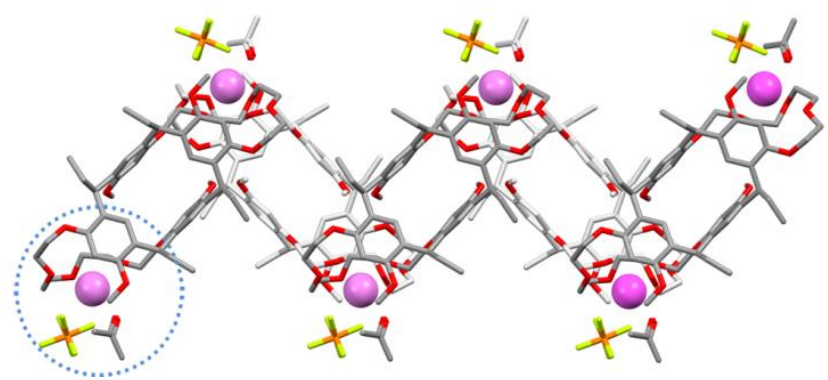

Figure 12. Crystal structures of $\mathbf{5} \mathbf{a} \cdot \mathbf{N a}{ }^{+}$complex and its helical chain. Hydrogen atoms are omitted for clarity and the exo-binding of the sodium cation is circled. ${ }^{16}$

Solid state structures of silver complexes of $\mathbf{5}$ show the preference of coordination to crown ether oxygens $(2.4-2.9 \AA)$ over the cation $\cdots \pi$ interaction $(2.4-2.7 \AA)$ as the silver coordinates only to one or two corners of the aromatic ring ( $\eta^{1}$ or $\eta^{2}$ fashion), whereas in alkali metal complexes the cation is located the middle of the aromatic ring in $\eta^{6}$ fashion. ${ }^{39}$ The smaller size also leaves room for the simultaneous solvent inclusion inside the cavity: the coordination sphere of the silver is filled by the coordination to solvent alcohol. The stoichiometry of binding was in most cases the expected 1:2, but also a crystal structure of 1:1 complex with a molecule of water occupying a second binding site was obtained indicating a competitive role of water in complexation.

The effect of the solvent for crystal packing was clearly evidenced in crystal structures of 5a silver complexes. ${ }^{39}$ Depending on the alcohol solvent, methanol, ethanol, $n$-propanol or isopropyl alcohol, the silver complexes of 5a adopt either a capsule (CCDC 813688), layer (CCDC 813690-813691) or a special 
kind of nanorod (CCDC 813689) packing motive. The nanorod packing motif crystallized form ethanol is composed of separate discs which each consists three outward facing $\mathbf{5} \mathbf{a} \cdot \mathbf{2} \mathbf{A g}^{+}$complexes of same inherent chirality (Figure 13a) leading to intracrystalline enantiomer separation. The discs are further stacked on top of each other forming nanosized hexagonal rods. The structures of capsular and layer structures crystallized from methanol and $n$-propanol or isopropyl alcohol, respectively, resemble closely the respective alkali metal structures. The reasons for differences in packing motifs were concluded to arise from the fit of the solvent inside the binding cavity simultaneously with silver ions: the inclusion of ethanol leads to adaption of resorcinarene core conformation to a highly twisted form, which creates a curvature in the complex structure and enables the assembly to discs instead of layers or capsules. A capsular packing motif, on the other hand, is possible with the inclusion of the smallest solvent methanol, which are completely inside the resorcinarene core forming a coordination bond to silver, hydrogen bonds to host and included water and to additional methanols filling the interstice between two capsule halves (Figure 13b). As for $n$-propanol and isopropyl alcohol are both clearly sterically too bulky to enable efficient capsule formation or additional hydrogen bonds to surroundings leaving a layer like packing governed by the closest packing effects the only possibility.

The other solid state silver complexes obtained with different alkyl chain lengths of the resorcinarene (5b and $\mathbf{5 h}$ ) showed no surprises. The silver complex of resorcinarene bis-crown $\mathbf{5 b}$ packed into a similar kind layered structure as $\mathbf{5 a} \cdot \mathbf{2} \mathbf{A g}^{+}$complex crystallized from $n$-propanol and isopropyl alcohol $(\text { CCDC } 833089)^{40}$ and as with alkali metal complexes the 1:1 silver complex of the long alkyl chain biscrown 5h (CCDC 833090) formed bilayers as respective alkali metal complexes. However, instead of capsules, the upper rims of the complexes are shifted horizontally about half the length of the upper rim.
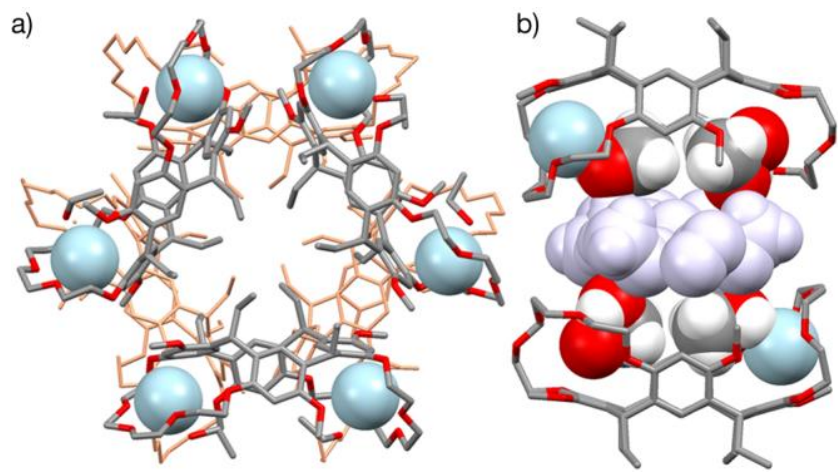

Figure 13. a) Nanorod structure of the resorcinarene bis-crown 5a silver complex (top view) and b) capsular packing motif of bis-crown 5a silver complex crystallized from methanol. Hydrogen atoms, ethanol molecules of the nanorod structure and counter anions of are omitted for clarity. ${ }^{39}$

The coordination of silver cations in bis-dithiacrown complex $\mathbf{1 2 a} \cdot \mathbf{2} \mathbf{A g}^{+}(\mathrm{CCDC} 855779$, $855781)$ is essentially similar to the coordination of silver to bis-crowns (5a, $\mathbf{5 b}$ and $\mathbf{5 h}$ ): silver cations occupy the both binding sites with a cation $\cdots \pi$ interaction to underneath aromatic ring in $\eta^{1}$ fashion $(2.8 \AA)$

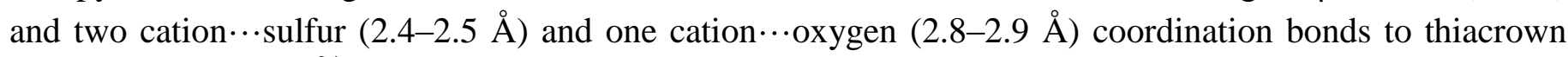
bridge. (Figure 14a). ${ }^{24}$ The complex units then line up as for example $\mathbf{5 a} \cdot \mathbf{2} \mathbf{R} \mathbf{b}^{+}$complexes (Figure 11c) except that the piles and layers are severely tilted. The binding behavior of bis-trithiacrown $\mathbf{1 2} \mathbf{b}$, on the other hand, differs clearly from other bis-crown alkali metal and silver complexes, as the host possesses both the endo- and exo-binding simultaneously (CCDC 855780). The silver cation inside the cavity interacts with three sulfur atoms of the thiabridge (2.6-2.7 $\AA$ ) and with the aromatic ring ( $\eta^{1}$ fashion, $3.9 \AA$ ). The endobound silver cation interacts also with altogether three sulfur atoms; except that it is encapsulated between two thiacrown moieties of neighboring opposite facing resorcinarenes (Figure 14b) and thus one of the three 
$\mathrm{Ag}^{+} \cdots$ sulfur interactions is with the adjacent host. The formed dimers connected by exo-bound silver pack into polymeric chains.

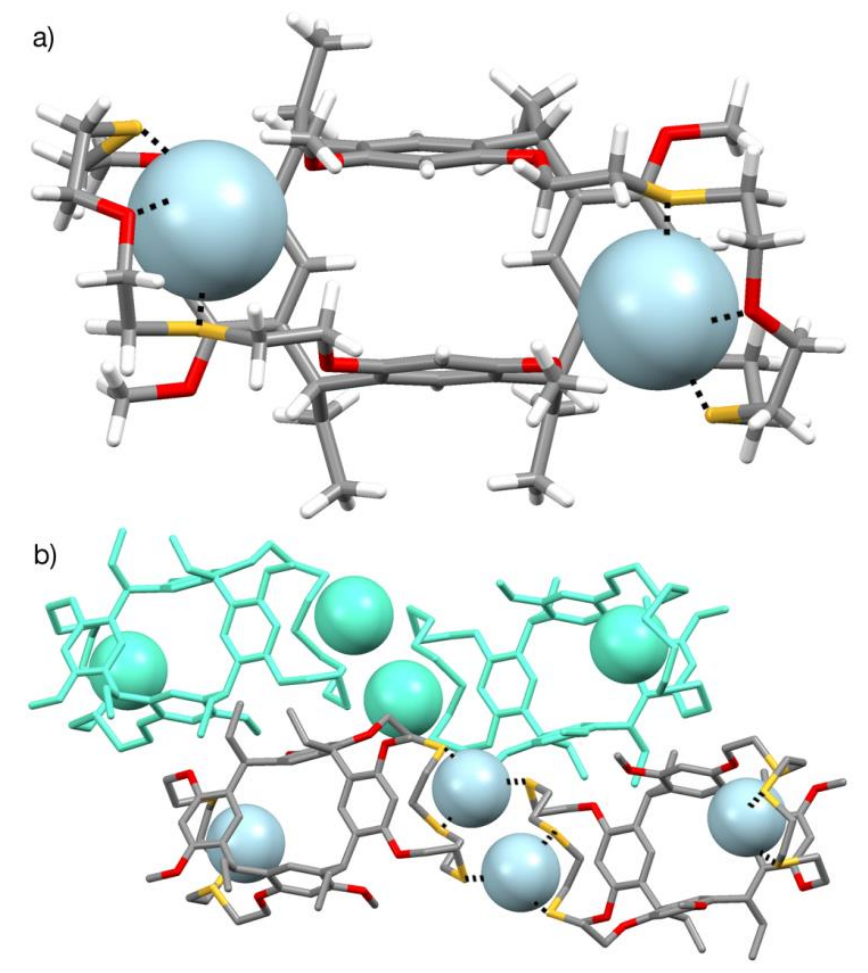

Figure 14. a) Top view of the bis-thiacrown 12a silver complex with two endo-bound silvers and b) packing of the bis-trithiacrown $\mathbf{1 2 b}$ silver complex with exo-bound silver ions connecting the adjacent hosts. ${ }^{24}$

\subsection{Calculated complexes}

Molecular modeling is also used to study the optimized structures of resorcinarene crown complexes and to obtain information about the ability of the crown ether moiety to change its shape and coordinate different sized guests. Kang et al. ${ }^{15}$ used Monte Carlo conformation search to study the empty resorcinarene cavitand bis-crown $\mathbf{3 b}$ (see chapter 3 ) but also to see whether the resorcinarene derivative could act as a sodium host. The MMFF optimized structure contained two sodium cations bound to three crown ether oxygen atoms with ideal coordination distances $(2.2-2.5 \AA)$. This result is supported by the picrate extraction studies which showed the selectivity of the bis-crown $\mathbf{3 b}$ toward sodium.

Stoll et al. ${ }^{27,28}$ exploited Kohn-Sham DFT calculations to study the structures of alkali metal complexes formed by the mono-substituted resorcinarene crowns $\mathbf{1 4 b}$ and $\mathbf{1 4 c}$. The sodium and potassium complexes of 14b with smaller crown moiety had two similar local minima: one with the crown moiety rotated away from the cavitand (sidewise-like complex, Figure 15a) and one with the crown turned over the cavitand (sandwich-like complex, Figure 15b). ${ }^{27}$ In all of the structures the metals are coordinated to four oxygens and nitrogen of the aza-crown, but additionally in the sidewise-like complexes the metal has a sixth interaction to the oxygen of the cavitand scaffold. Energetically, both metal complexes prefer the sidewise conformation $\left(\Delta \mathrm{E}_{1}<65-75 \mathrm{kJmol}^{-1}\right)$ because of the increased number of metal interactions and the shorter metal-oxygen distances (2.33-2.46 $\AA$ for $\mathrm{Na}^{+}$and 2.73-2.83 for $\mathrm{K}^{+}$) compared to the sandwich conformation (2.39-2.49 $\AA$ for $\mathrm{Na}^{+}$and 2.77-2.85 for $\mathrm{K}^{+}$). For the mono-substituted cavitand 14c with the bigger azacrown the cesium complex in addition to the potassium complex was calculated. ${ }^{28}$ In contrast to the calculation made with 14b only sandwich-like conformation was used for the structure optimization and two coordination isomers were preselected as starting configurations: one in which the metal is closer to the azacrown and one in which the metal is closer to the resorcinarene cavity (Figure $15 \mathrm{c}$ and $\mathrm{d}$ ). In the first 
structure potassium forms seven coordination bonds to oxygens of which six is between the crown moiety and one with the cavitand, and in the latter structure the total number of interactions is six of which one is to nitrogen, three to crown oxygens and two to the cavity. In the case of cesium the coordination number was eight and there were not substantial differences between the energy minima of the different conformations.

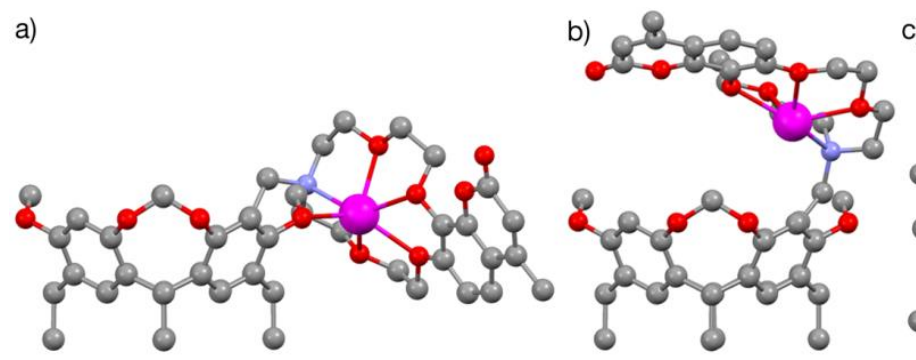

c)

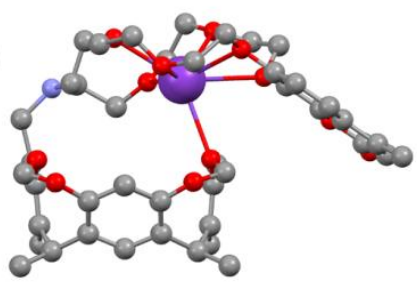

d)

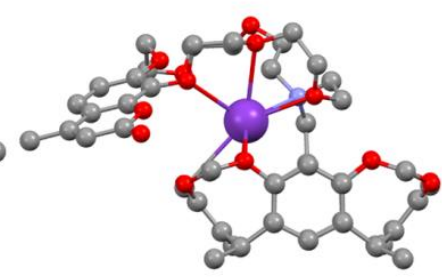

Figure 15. Calculated structures for a) the sidewise and b) for the sandwich-like conformations of $\mathbf{1 4 b} \cdot \mathbf{N a}$ complex and for two (c, d) $\mathbf{1 4 c} \cdot \mathbf{K}$ complexes. Structures are drawn from the given Cartesian coordinates. ${ }^{27,28}$

\section{Potential for applications}

\subsection{Transporter mimics}

Ability to bind different cations have encouraged researchers to exploit these properties in resorcinarene crown based transporters as many of the cations are biologically active, for example sodium and potassium in the nerve impulse transmission. Kang et al. ${ }^{15}$ tested competitive transport of alkali metal cations using bis-crown[4]cavitand $\mathbf{3 b}$ as a transporter. The method chosen was bulk liquid membrane (BLM) method, also referred as U-tube study, where ions are transported from an aqueous source phase through an organic liquid membrane (chloroform) that contains the transporter to an aqueous receiving phase. ${ }^{41}$ The results correlated with the picrate experiments; transportation of $\mathrm{Na}^{+}(17.5 \%)$ is favored over other cations $\left(\mathrm{Li}^{+} 0 \%, \mathrm{~K}^{+} 2.12 \%, \mathrm{Mg}^{2+} 0.38 \%, \mathrm{Ca}^{2+} 0 \%\right)$.

BLM $^{42}$ method was also used by Beer and his co-workers ${ }^{32}$ in studies of transport ability and selectivity of ion channel mimics, crown ether resorcinarenes $\mathbf{1 8 a}-\mathbf{b}$ in order to better understand the functions and mechanisms of biological transport processes. The studies showed that the resorcinarene derivatives $\mathbf{1 8 a}$ and $\mathbf{1 8 b}$ act as efficient transporters for potassium (mean flux $=1.10 \times 10^{-6}$ and $10.05 \times 10^{-6}$ mol $\mathrm{h}^{-1}$, respectively). When comparing selectivity of transportation of sodium, potassium and cesium, resorcinarene 18a with a smaller crown ether moiety transports potassium substantially faster than either sodium $\left(8.30 \times 10^{-7} \mathrm{~mol} \mathrm{~h}^{-1}\right)$ or cesium $\left(8.50 \times 10^{-7} \mathrm{~mol} \mathrm{~h}^{-1}\right)$. On the other hand, with resorcinarene $\mathbf{1 8 b}$ the transport of sodium $\left(4.04 \times 10^{-7} \mathrm{~mol} \mathrm{~h}^{-1}\right)$ is slower than the transport of both cesium $\left(1.04 \times 10^{-6} \mathrm{~mol} \mathrm{~h}^{-1}\right)$ and potassium. Thus, 18a shows specific selectivity towards potassium, whereas $\mathbf{1 8 b}$ transports cesium and potassium with equal rate.

Membrane separation systems can be utilized in the removal of toxic and radioactive ions, for example from environment or from waste. Thus, in contrary to the above-mentioned cation studies, Lamb et $a l .{ }^{29}$ were encouraged to study a transportation of anions through a membrane using tetrasubstituted resorcinarene cavitand crown 16a. However, the method is still based on cation binding ability of 16a, since as the carrier in the membrane binds to cation from the source phase, anion must be also transported 
simultaneously to maintain the charge neutrality. BLM experiments with permeability value to represent the transportation was done to $\mathrm{NO}_{3}{ }^{-}, \mathrm{ClO}_{4}{ }^{-}$and $\mathrm{ReO}_{4}{ }^{-}$anions, which were chosen as subjects of studies because of their different sizes, shapes and hydration energies. $\mathrm{ReO}_{4}{ }^{-}$is also a nonradioactive analog to pertechnetate which is a byproduct of nuclear waste. The transportation of $\mathrm{NO}_{3}{ }^{-}$and $\mathrm{ClO}_{4}^{-}$was minimal when $\mathrm{Li}^{+}$was used as a counter cation since it is too small to bind to aza-18-crown-6. When using larger alkali cations, $\mathrm{Na}^{+}$and $\mathrm{K}^{+}$, known to bind with the azacrown permeability values increased substantially. $\mathrm{Na}^{+}$and $\mathrm{K}^{+}$complexes showed selectivity towards $\mathrm{ClO}_{4}^{-}\left(P=178-198 \times 10^{8} \mathrm{~m} / \mathrm{s}\right)$ and $\mathrm{ReO}_{4}{ }^{-}\left(P=224-236 \times 10^{8} \mathrm{~m} / \mathrm{s}\right)$ as they were transported over $\mathrm{NO}_{3}{ }^{-}\left(P=10-21 \times 10^{8} \mathrm{~m} / \mathrm{s}\right)$ from dichloromethane to water phase. The transmission metal cation complex $\mathrm{Pb}^{+}$with $\mathbf{1 6 a}$, on the other hand, favored transportation of $\mathrm{NO}_{3}{ }^{-}\left(P=117 \times 10^{8} \mathrm{~m} / \mathrm{s}\right)$ over $\mathrm{ClO}_{4}{ }^{-}\left(P=16 \times 10^{8} \mathrm{~m} / \mathrm{s}\right)$. The experiment of a mixture of $\mathrm{Na}^{+} / \mathrm{K}^{+}$ did not effect on the magnitudes of permeability values, but when the selectivity towards anions is different as with $\mathrm{K}^{+}$and $\mathrm{Pb}^{+}$, all transportation values of different anions are clearly decreased $\left(\mathrm{P}=21-33 \times 10^{8} \mathrm{~m} / \mathrm{s}\right)$. As a result, the transportation of different anion by $\mathbf{1 6 a}$ heavily depends on the composition of the mixture if one cation in the mixture inhibits anion transfer, it may inhibit all transportations even if a conductive cation is present.

\subsection{Pseudorotaxanes}

Rotaxanes, mechanically inter-locked molecules, have gained attention among scientists due to their potential as molecular machines and devices. Pseudorotaxanes is a class of rotaxanes that can dissociate into its two components without breaking covalent bonds since the inner linear molecule lacks the bulky groups at the ends which would lock the surrounding cycle on its position. Ihm and Paek ${ }^{31}$ used tetrasubstituted dibenzo[25] crown-8 cavitand $\mathbf{1 6 b}$ and a tetrakis $\left(m\right.$-ammonium)cavitand $20\left[\mathrm{PF}_{6}{ }^{-}\right]_{4}$ to form a pseudorotaxane type heterodimer $\mathbf{1 6} \mathbf{b} \cdot \mathbf{2 0}\left[\mathrm{PF}_{6}{ }^{-}\right]_{4}$ held together by hydrogen bonds between ammoniums and crown ethers (Figure 16). The idea was to form a new kind of opening and closing self-assembled capsule that could be used in encapsulating guest molecules. The solvent and temperature effects on the stability of the heterodimer were studied by ${ }^{1} \mathrm{H}$ NMR. In a non-polar solvent $\mathrm{CDCl}_{3}$ the dimer was observed but in more polar solvents, such as acetone, methanol or DMSO, only separate signals of $\mathbf{1 6 b}$ and 20 were observed most likely due to the interference of the solvent with the hydrogen bond network keeping the complex together. The addition of $10 \mu \mathrm{l}$ of DMSO- $d_{6}$ into the $\mathrm{CDCl}_{3}$ solution $(600 \mu \mathrm{l})$ of $\mathbf{1 6} \mathbf{b} \cdot \mathbf{2 0}\left[\mathrm{PF}_{6}\right]_{4}$ induced the signals of free $\mathbf{1 6 b}$ and $20\left[\mathrm{PF}_{6}^{-}\right]_{4}$ in addition to the signals of the complex. In a $3.2 \%$ solution of DMSO$d_{6} / \mathrm{CDCl} 3(20 / 600 \mu \mathrm{l})$ the capsule was completely dissociated. The thermodynamic studies showed that at $20{ }^{\circ} \mathrm{C}$ the capsule is stable but when the temperature is increased up to $60{ }^{\circ} \mathrm{C}$ the signals of $\mathbf{1 6} \mathbf{b}^{\circ} \mathbf{2 0}\left[\mathrm{PF}_{6}\right]_{4}$ disappear and free $\mathbf{1 6} \mathbf{b}$ emerges. The signals of the cavitand 20 are not observed, as it is insoluble in nonpolar solvents on its own. When the temperature is cooled back to $20{ }^{\circ} \mathrm{C}$ the heterodimer $\mathbf{1 6} \mathbf{b} \cdot \mathbf{2 0}\left[\mathrm{PF}_{6}\right]_{4}$ is reformed indicating that the formation of the dimer can be reversibly controlled by temperature. However, no evidence was found that the capsule $\mathbf{1 6} \mathbf{b} \cdot \mathbf{2 0}\left[\mathrm{PF}_{6}^{-}\right]_{4}$ could complex guests as the addition of guests to the NMR solution caused the dimer to collapse.

$\ddagger P=\frac{\left(C_{S} / C_{0}\right) V / S}{t}, C_{S}=$ the concentration in sample $(\mathrm{M}), C_{0}=$ initial concentration of the source phase $(\mathrm{M}), V=$ the volume of the source phase $(\mathrm{L}), S=$ the membrane surface area $\left(\mathrm{m}^{2}\right), t=$ time $(\mathrm{s})$. 


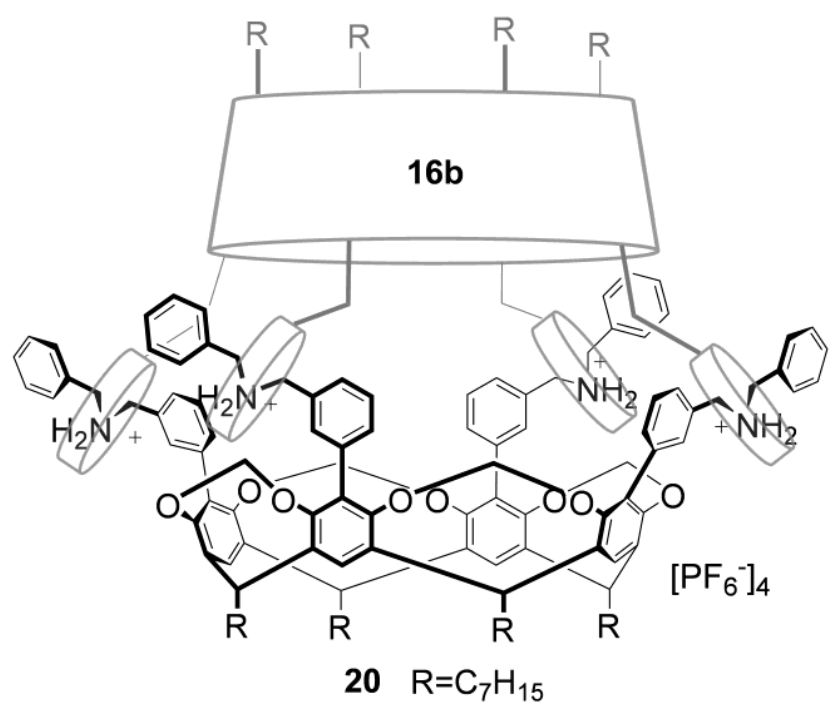

Figure 16. Schematic presentation of the rotaxane formed by resorcinarene cavitand crown $\mathbf{1 6} \mathbf{b}$ and tetrakis $\left(m\right.$-ammonium)cavitand $\mathbf{2 0}\left[\mathrm{PF}_{6}^{-}\right]_{4}$.

\subsection{Solid lipid nanoparticle}

Nature of calixarenes and resorcinarenes makes them ideal for preparation of solid lipid nanoparticles (SLNs), which have shown potential to act as drug carriers. Knowing that resorcinarene biscrowns 5a-b, 5d and $\mathbf{5 f}-\mathbf{5 h}$ and their metal complexes can form different kinds of highly organized structures their ability to form SLNs, as well as the dependency of SLN properties on the alkyl chain lengths were investigated. ${ }^{40}$ The particles were prepared by a solvent replacement method ${ }^{43}$ where water was added to a THF solution of a bis-crown while vigorously stirring. The dynamic scattering experiment as well as SEM images showed that the obtained SLNs were 220-320 nm in diameter depending on their alkyl chain lengths. As expected, the diameter increased, the longer the alkyl chain length became. The prepared SLNs were relatively stable as they survived the vacuum treatment needed for the sample preparation of the SEM and also after several months most of the SLN samples remained unchanged. Surprisingly, also the biscrowns with short alkyl chains $\left(\mathrm{C}_{2}, \mathrm{C}_{3}\right.$ and $\left.\mathrm{C}_{4}\right)$ formed solid lipid nanoparticles even though in the solid state they do not show amphiphilic characteristics, as they do not pack in a bilayer manner. The SLN behaviour is probably due to the bridging which locks the macrocycle into a boat conformation, and thus separates well the hydrophilic side from the hydrophobic side of the compounds.

\subsection{Antibacterial layers}

The silver binding ability of resorcinarene bis-crowns 5 was further utilized in studies of antibacterial effect of silver complexes and whether the resorcinarene scaffold offers any benefit compared to native silver, which is known to have antibacterial effects. ${ }^{39,40}$ Especially the layer forming amphiphilic long alkyl chain derivative $\mathbf{5 h}\left(\mathrm{R}=\mathrm{C}_{11} \mathrm{H}_{23}\right)$ was chosen as a target host due to its capacity to form a monolayer at the air-water interface. Langmuir balance technique showed that in the presence of silver ions $\left(\mathrm{AgNO}_{3}\right)$ the monolayer has a small increase in the surface pressure $\left(35 \mathrm{mN} \mathrm{m}^{-1}\right)$ and in the surface area (163 $\AA^{3} /$ molecule) compared to a pure bis-crown $\mathbf{5 h}$ monolayer $\left(33 \mathrm{mN} \mathrm{m}^{-1}, 157 \AA^{3} /\right.$ molecule). These results clearly indicate that also in thin films the amphiphilic hosts interact with silver ions, thus modifying the properties of the monolayer. The antibacterial effect of the ampihipilic layer formed by the $\mathbf{5 h}$ silver complexes was compared to a hydrophobic glass slide without any amphiphilic layer, a pure bis-crown layer without silver on a glass slide and to a glass slide dipped in $\mathrm{AgNO}_{3}$ (Figure 17). The effect on bacterial growth was determined from microscope images after 5 hours of exposure of the samples on the agar gel covered with $E$. coli bacteria. As expected the glass slide had insignificant effect on the bacterial growth as 
93\% of the bacteria remained on the gel while $\mathrm{AgNO}_{3}$ covered glass caused about $30 \%$ loss of bacteria and the Langmuir-Blodgett (LB) film of the bis-crown $\mathbf{5 h}$ without silver left $88 \%$ of the agar gel covered with $E$. coli. Remarkably, the LB film of $\mathbf{5 h}$ silver complex notably decreased the bacterial coverage on the agar gel - only $7 \%$ of the gel was covered with bacteria after the experiment although the concentration of silver ions in complex film is very low, approximately $90 \mathrm{nM}$ at its best, which is more than 200-fold lower than the complete inhibitory concentration (CIC) of silver for E. coli $(18.9 \mu \mathrm{M}) .{ }^{44}$ It was suggested that the benefit of using these silver complex LB films is due to low concentration of silver ions and the close proximity of the silver releasing layer to bacteria. These properties prevent the bulk effect of the silver ions in the culture medium which would not inhibit the bacterial growth.

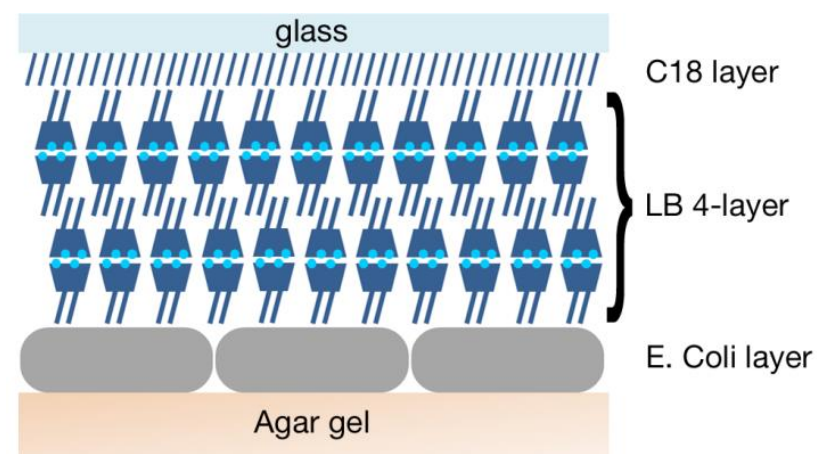

Figure 17. Schematic presentation of the antibacterial experiment performed with silver complexes of resorcinarene bis-crown $\mathbf{5 h}$.

\section{Conclusion}

In conclusion, resorcinarene crowns have proven to be a synthetically and structurally versatile host group with a potential to applications. The crown moieties have been attached to the resorcinarene scaffold by bridging, as podand-type arms or as part of the lower rim chains, when they are introduced to resorcinarene in native synthesis without further need for modification. The main target in functionalizing resorcinarenes has been their ability to act as host molecules for different cations. Thus, in addition to traditional crown ethers thiacrowns have also been synthetized to enhance selectivity toward softer cations. The complexation studies in solution showed that the highest binding constants $\left(\log K=\sim 4-5 \mathrm{M}^{-1}\right)$ toward different alkali metals were obtained using bridged resorcinarene bis-crowns 5 and mono-substituted resorcinarene azacrown podands 14. The reasonable binding constants do not reach as high values as calix $[n]$ crowns whose binding affinities toward alkali metals are at best multiple times higher $\left(\log \mathrm{K}=\sim 7-9 \mathrm{M}^{-1}\right.$ ), probably because the degree of preorganization is higher in calixarenes. However, selectivity toward certain alkali metals has been achieved by chancing the size of the crown ether bridge or by adding aromaticity to the crown bridge. The binding affinity of resorcinarene bis-thiacrowns to silver $\left(\log \mathrm{K}=\sim 8-9 \mathrm{M}^{-1}\right)$ has reached the magnitude of calix $[n]$ crowns toward alkali metals indicating that there are still great potential to improve the binding properties of resorcinarene crowns with careful design and synthetic modification.

Even though the chemistry of resorcinarene crowns is not as well known as the chemistry of calix $[n]$ crowns, preliminary potential for applications have already been reported as transporter mimics of biologically active alkali metals and anions, and in a construction of a pseudorotaxane assembly, solid lipid nanoparticles and thin layers with antibacterial activity. Since the previous review on calix $[n]$ arene crowns mentioning also resorcinarene crowns published in $2008,{ }^{7}$ a lot of progress has been accomplished with the latter group of supramolecular hosts. As their structural characteristics are already well defined, the basic synthesis methods are explored and the primary application studies have been promising it is likely that 
study of resorcinarene crowns will continue with the aim of creating yet larger functional nanosized assemblies as well as potential applications, for example, in the fields of transportation and separation.

\section{References}

1. Review: Steed, J. W. Coord. Chem. Rev. 2001, 215, 171.

2. See for example: (a) Prodi, L.; Bolletta, F.; Zaccheroni, N.; Watt, C. I. F.; Mooney, N. J. Chem. Eur. J. 1998, 4, 1090; (b) Breccia, P.; Cacciapaglia, R.; Mandolini, L.; Scorsini, C. J. Chem. Soc., Perkin Trans. 2 1998, 1257; (c) Yan, Y.; Zhao, W.; Bhagavathy, G. V.; Faurie, A.; Mosey, N. J.; Petitjean, A. Chem. Commun. 2012, 48, 7829; (d) Park. Y. J.; Cook, S. A.; Sickerman, N. S.; Sano, Y.; Ziller, J. W.; Borovik, A. S. Chem. Sci. 2013, 4, 717.

3. (a) Zolgharnein, J.; Shahmoradi, G.; Amani, S. J. Incl. Phenom. Macrocycl. Chem. 2008, 60, 163; (b) Aragoni, M. C.; Arca, M.; Bencini, A.; Biangini, S.; Blake, A. J.; Caltagirone, C.; Demartin, F.; De Filippo, G.; Devillanova, F. A.; Garau, A.; Gloe, K.; Isaia, F.; Lippolis, V.; Valtancoli, B.; Wenzel, M. Inorg. Chem. 2008, 47, 8391; (c) Fuangswasdi, S.; Kaveevivitchai, N.; Tuntulani, T.; Savage, P. B. J. Solution Chem. 2008, 37, 45.

4. (a) Schulz, R. A.; White, B. D.; Dishong, D. M.; Arnold, K. A; Gokel, G. W. J. Am. Chem. Soc. 1985, 107, 6659; (b) Chang, T.; Heiss, A. M.; Cantrill, S. J.; Fyfe, M. C. T.; Pease, A. R.; Rowan, S. J.; Stoddart, J. F., White, A. J. P.; Williams, D. J. Org. Lett. 2000, 2, 2947; (c) Späth, A.; König, B. Beilstein J. Org. Chem. 2010, 6, no pp. given.

5. (a) Valeur, B.; Leray, I. Coord. Chem. Rev. 2000, 205, 3; (b) Callan, J. F.; de Silva, A. P.; Magri, D. C. Tetrahedron, 2005, 61, 8551; (c) Mandl, C. P.; König, B. J. Org. Chem. 2005, 70, 670; (d) Gruber, B.; Stadlbauer, S.; Späth, A.; Weiss, S.; Kalinina, M.; König, B. Angew. Chem. Int. Ed. 2010, 49, 7125.

6. For a review see for example: (a) Raymo, F. M.; Stoddart, J. F. Chem. Rev. 1999, 99, 1643; (b) Schalley, C. A.; Beizai, K.; Vögtle, F. Acc. Chem. Res. 2001, 34, 465.

7. For a review see: Salorinne, K.; Nissinen, M. J. Incl. Phenom. Macrocycl. Chem. 2008, 61, 11.

8. For a review see: a) Sliwa, W.; Kozlowski, C. in Calixarenes and Resorcinarenes, Wiley-VCH, Weinheim, 2009; b) Timmerman, P.; Verboom, W.; Reinhoudt, D. N. Tetrahedron 1996, $52,2663$.

9. See for example: (a) Casnati, A.; Pochini, A.; Ungaro, R.; Ugozzoli, F.; Arnaud, F.; Fanni, S.; Schwing, M.-J.; Egberink, R. J. M.; de Jong, F.; Reinhoudt, D. N. J. Am. Chem. Soc. 1995, 117, 2767; (b) Pappalardo, S.; Petringa, A.; Parisi, M. F.; Ferguson, G. Tetrahedron Lett. 1996, 37, 3907; (c) Arnaud-Neu, F.; Ferguson, G.; Fuangswasdi, S.; Notti, A.; Pappalardo, S.; Parisi, M. F.; Petringa, A. J. Org. Chem. 1998, 63, 7770; (d) Tu, C.; Surowiec, K.; Bartsch, R. A. Tetrahedron, 2007, 63, 4184.

10. See for example: (a) Arduini, A.; Domiano, L.; Pochini, A.; Secchi, A.; Ungaro, R.; Ugozzoli, F.; Struck, O.; Verboom, W.; Reinhoudt, D. N. Tetrahedron, 1997, 53, 3767; (b) Asfari, Z.; Lamare, V.; Dozol, J.-F.; Vicens, J. Tetrahedron Lett. 1999, 40, 691; (c) Vicens, J. J. Incl. Phenom. Macrocycl. Chem. 2006, 55, 193; (d) Roper, E. D.; Talanov, V. S.; Butcher, R. J.; Talanova, G. G. Supramol. Chem. 2008, 20, 217.

11. Sliwa, W.; Deska, M. Chem. Heterocycl. Compd. 2002, 38, 646.

12. McIldowie, M. J.; Mocerino, M.; Skelton, B. W.; White, A. H. Org. Lett. 2000, 2, 3869.

13. Higler, I.; Boerrigter, H.; Verboom, W.; Kooijman, H.; Spek, A. L.; Reinhoudt, D. N. Eur. J. Org. Chem. $1998,1597$.

14. Cram, D. J.; Jaeger, R.; Deshayes, K. J. Am. Chem. Soc. 1993, 115, 10111.

15. Kang, A.; Kim, S. K.; Nakamura, K.; Park, J. H.; Yoon, Y. J.; Lee, K. D.; Yoon, J. Tetrahedron Lett. $2005,46,245$.

16. Salorinne, K.; Nissinen, M. Org. Lett. 2006, 8, 5473.

17. Helttunen, K.; Salorinne, K.; Barboza, T.; Campos Barbosa, H.; Suhonen, A.; Nissinen, M. New. J. Chem. $2012,36,789$.

18. Salorinne, K.; Tero, T.-R.; Riikonen; K.; Nissinen, M. Org. Biomol. Chem. 2009, 7, 4211.

19. Tero, T.-R.; Salorinne, K.; Lehtivuori, H.; Ihalainen, J. A.; Nissinen, M. manuscript in preparation.

20. Katritzky, A. R.; Murugan, R.; Siskin, M. Energy \& Fuels, 1990, 4, 531.

21. Cai, Y.; Castro, P. P.; Gutierrez-Tunstad, L. M. Tetrahedron Lett. 2008, 49, 2146.

22. Castro, P. P.; Zhao, G.; Masangkay, G. A.; Hernandez, C.; Gutierrez-Tunstad, L. M. Org. Lett. $2004,6,333$.

23. Salorinne, K.; Nissinen, M. Tetrahedron 2008, 64, 1798.

24. Salorinne, K.; Nauha, E.; Nissinen, M. Chem. Asian J. 2012, 7, 809.

25. Morikawa, O.; Nakanishi, K.; Miyashiro, M.; Kobayashi, K.; Konishi, H. Synthesis, 2000, 233.

26. Hamada, F.; Ito, S.; Narita, M.; Nashirozawa, N. Tetrahedron Lett. 1999, 40, 1527.

27. Stoll, I.; Brodbeck, R.; Wiegmann, S.; Eberhard, J.; Kerruth, S.; Neumann, B.; Stammler, H.-G.; Mattay, J. Eur. J. Org. Chem. 2008, 5231.

28. Stoll, I.; Eberhard, J.; Brodbeck, R.; Eisfeld, W.; Mattay, J. Chem. Eur. J. 2008, 14, 1155.

29. Lamb, J. D.; Morris, C. A.; West, J. N.; Morris, K. T.; Harrison, R. G.; J. Membr. Sci. 2008, $321,15$.

30. Gardner, J. S.; Peterson, Q. P.; Walker, J. O.; Jensen, B. D.; Adhikary, B.; Harrison, R. G.; Lamb, J. D. J. Membr. Sci. 2006, 277, 165.

31. Ihm, C.; Paek, K. Tetrahedron Lett. 2007, 48, 3263.

32. Wright, A. J.; Matthews, S. E.; Fischer, W. B.; Beer, P. D. Chem. Eur. J. 2001, 7, 3474.

33. Högberg, A. G. S. J. Org. Chem. 1980, 45, 4498.

34. Poleska-Muchaldo, Z.; Luboch, E.; Biernat, J. F. Synth. Commun. 2008, 38, 3062.

35. Kim, S. K.; Vicens, J.; Park, K.-M.; Lee, S. S.; Kim, J. S. Tetrahedron Lett. 2003, 44, 993.

36. Salorinne, K.; Nissinen, M. CrystEngComm 2009, 11, 1572. 
37. Abis, L.; Dalcanale, E.; Du Vosel; A.; Spera, S. J. Org. Chem. 1988, 53, 5475.

38. Hynes, M. J. J. Chem. Soc., Dalton Trans. 1993, 311.

39. Salorinne, K.; Lopez-Acevedo, O.; Nauha, E.; Häkkinen, H.; Nissinen, M. CrystEngComm 2012, $14,347$.

40. Helttunen, K.; Moridi, N.; Shahgaldian, P.; Nissinen, M. Org. Biomol. Chem. 2012, 10, 2019.

41. Maruyama, K.; Tsukube, H.; Araki, T. J. Am. Chem. Soc. 1982, 104, 5197.

42. Rebek, J. Jr.; Askew, B.; Nemeth, D.; Parris, K. J. Am. Chem. Soc. 1987, 109, 2432.

43. (a)Shahgaldian, P.; Da Silva, E.; Coleman, A. W.; Rather, B.; Zaworotko, M. J. Int. J. Pharm. 2003, 253, 23. (b) Gualbert, J.; Shahgaldian, P.; Lazar, A.; Coleman, A. W. J. Inclusion Phenom. Macrocyclic Chem. 2004, 48, 37.

44. Zhao G.; Stevens, S. E. Jr. BioMetals, 1998, 11, 27. 


\section{Biographical Information}

Tiia-Riikka Tero was born in Jyväskylä, Finland in 1987. She received her bachelor's degree in organic chemistry in 2009 and M.Sc. in 2011 from University of Jyväskylä, Finland. She is currently working under Prof. Maija Nissinen's mentorship as a PhD student funded by the National Doctoral Programme in Nanoscience (NGS-Nano).

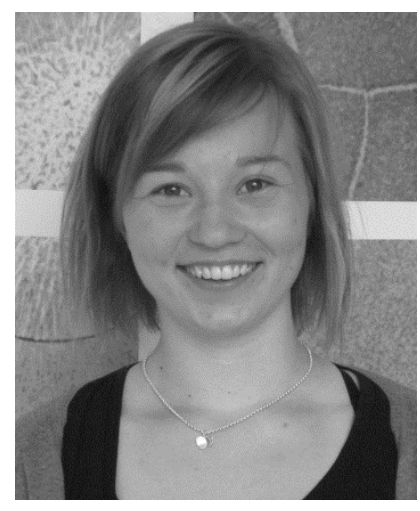

Maija Nissinen was born in Nivala, Finland 1974. She got her M.Sc. degree in 1997 and Ph.D. in 2001 from University of Jyväskylä, Finland. After her Ph.D. she worked as a head of academic affairs at the Faculty of Mathematics and Science and as a post doctoral researcher 2001-2003 in research group of professor Rissanen. 2003 she received a position of academy research fellow granted by Academy of Finland, which she held until 2006, when she was selected to a tenure track professorship at Department of Chemistry, University of Jyväskylä. Currently she is working as a full professor in Department of Chemistry, University of Jyväskylä. Her research interests are supramolecular and nanochemistry, especially resorcinarene crowns and metal nanoparticles, and solid state structural chemistry. She has published about 100 scientific publications.

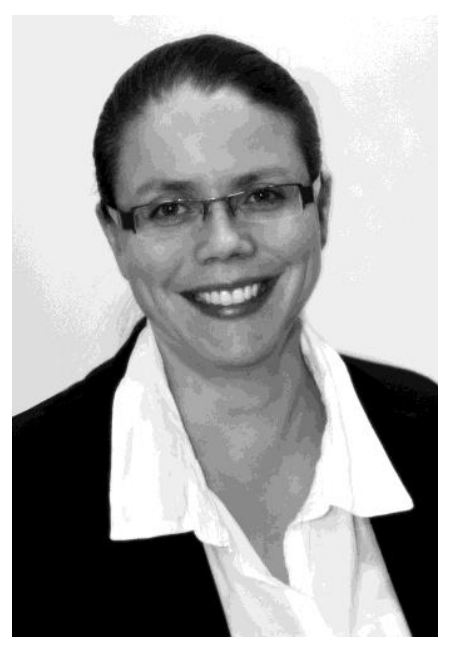


Graphical Abstract

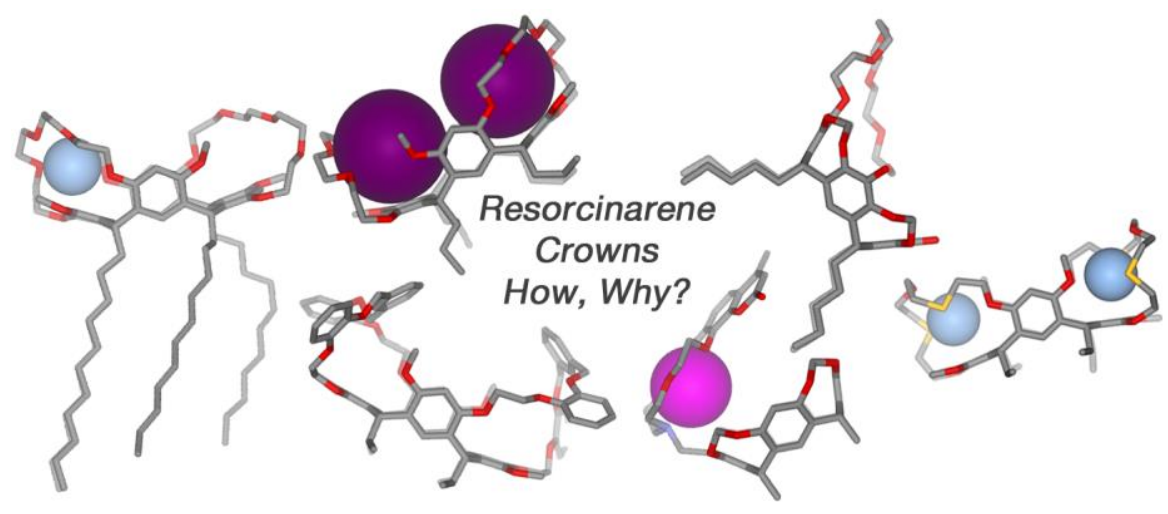

